1 Title: Digital health interventions for children and young people with mental health

2 problems: a systematic and meta-review

3 Abbreviated title: DHIs for children and young people's mental health

4 Authors: Chris Hollis ${ }^{1,2}$, Caroline J Falconer ${ }^{1,2}$, Jennifer L Martin ${ }^{1,2}$, Craig Whittington ${ }^{3}$, 5 Sarah Stockton ${ }^{4}$ Cris Glazebrook ${ }^{1,2}$ \& E Bethan Davies ${ }^{1,2}$

\title{
6 Affiliations:
}

$7 \quad{ }^{1}$ Division of Psychiatry and Applied Psychology, School of Medicine, University of

8 Nottingham, Nottingham, UK

92 NIHR MindTech Healthcare Technology Co-operative, Institute of Mental Health, 10 University of Nottingham, Nottingham, UK

113 University College London, London, UK

${ }^{4}$ Department of Psychiatry, Warneford Hospital, Oxford, UK 


\section{ABSTRACT}

17 Background: Digital health interventions (DHIs), including computer-assisted therapy, smartphone apps and wearable technologies, are heralded as having enormous potential to improve uptake and accessibility, efficiency, clinical effectiveness and personalisation of mental health interventions. It is generally assumed that DHIs will be preferred by children and young people (CYP) given their ubiquitous digital activity. However, it remains uncertain whether: DHIs for CYP are clinically and cost-effective, CYP prefer DHIs to traditional services, DHIs widen access and how they should be evaluated and adopted by mental health services. This review evaluates the evidence-base for DHIs and considers the key research questions and approaches to evaluation and implementation.

Methods: We conducted a meta-review of scoping, narrative, systematic or metaanalytical reviews investigating the effectiveness of DHIs for mental health problems in CYP. We also updated a systematic review of RCTs of DHIs for CYP published in the last three years.

Results: 21 reviews were included in the meta-review. The findings provide some support for the clinical benefit of DHIs, particularly computerised CBT (CCBT), for depression and anxiety in adolescents and young adults. The systematic review identified 30 new RCTs evaluating DHIs for ADHD, autism, anxiety, depression, psychosis, eating disorders and PTSD. The benefits of DHIs in managing ADHD, autism, psychosis and eating disorders are uncertain, and evidence is lacking regarding the cost-effectiveness of DHIs.

Conclusions: Key methodological limitations make it difficult to draw definitive conclusions from existing clinical trials of DHIs. Issues include variable uptake and engagement with DHIs, lack of an agreed typology/taxonomy for DHIs, small sample sizes, lack of blinded outcome assessment, combining different comparators, short-term followup and poor specification of the level of human support. Research and practice recommendations are presented that address the key research questions and methodological issues for the evaluation and clinical implementation of DHIs for CYP.

Keywords: digital health, mental health, eHealth, methodology, randomised controlled trials, prevention 


\section{INTRODUCTION}

The past decade has seen a significant increase in the prevalence of mental health problems in children and young people (CYP) (Collishaw, 2015), with the worldwide prevalence rate of mental disorders in CYP now estimated to be $13.4 \%$ (Polanczyk, Salum, Sugaya, Caye \& Rohde, 2015). With increasing demand on child and adolescent mental health services (CAMHS), the access to evidence-based psychological treatments is severely limited by the supply of trained mental health practitioners, and it is estimated that $75 \%$ of CYP with mental health problems in the U.K. receive no treatment at all (Davies, 2014).

Digital technology and digital health interventions (DHIs) have been heralded as offering enormous potential as scalable tools to improve outcomes, to widen access and meet the increasing demand on mental health services. Suggested benefits of DHIs include improved uptake and accessibility, efficiency, clinical effectiveness and personalisation of mental health interventions. Given the strength of these claims with respect to health service policy and implementation, it is important that they are tested empirically.

It is commonly assumed that because young people are ubiquitous consumers and users of digital technology for social and recreational purposes, they will be equally enthusiastic recipients of DHIs (Johnson, Fuchs, Horvath \& Scal, 2015). These assumptions may often drive digital health service transformation but are rarely tested. The ability of digital technology to deliver automated and self-directed interventions is frequently argued as a way to improve access, ease pressures on face-to-face (FtF) services, and avoid the reported stigma associated with physical visits to mental health services (Hollis et al., 2015).

The range and scope of DHIs and digitally-delivered healthcare services have evolved rapidly since Eysenbach's (2001) initial description of internet-enabled or computerenabled interventions. These early DHIs in the mental health field typically contained static content with limited interactivity and were 'fixed' in terms of access (e.g. via a PC or 
laptop, requiring a wired internet connection), meaning that users needed to be in a specific location to access the intervention. Examples of these DHIs include computerised cognitive behavioural therapy (CCBT) (see Table 1. for a glossary of digital health terminology) which typically mimics FtF-delivered CBT sessions by providing a series of discrete modules that users complete sequentially over a specific time period. Recent advances in computerised technologies and programming has led to the possibility of CCBT interventions becoming more interactive and adaptable for young people though use of gamification and 'serious games' (Fleming et al., 2014). DHIs also include telecommunications processes (e.g. text messaging, emailing, video conferencing) to support remote synchronous and asynchronous delivery of therapy (Boogerd, Arts, Engelen \& van de Belt, 2015; Naslund, Marsch, McHugo \& Bartels, 2015; Zulman et al., 2015). These approaches are often referred to as 'tele-health', 'tele-medicine' or 'telepsychiatry' and fall within the broad description of 'eHealth' (see Table 1.).

Over the last decade, the increased popularity and availability of mobile digital technologies, such as smartphones and wearable technologies, has led to the development and evaluation of mobile DHIs, also known as 'mHealth' (see Table 1.). mHealth DHIs include smartphone applications ('apps'), remote monitoring and tracking devices, and wearable computers (e.g. smartwatches, virtual reality headsets). Remote active and passive monitoring of parameters, such as mood, activity and sleep, are now being integrated with therapeutic interventions. Hence, the distinction between mHealth digital monitoring and interventions is likely to become increasingly blurred.

DHIs vary widely with respect to design, mode of delivery and the mechanisms through which they aim to change mental health and wellbeing. Typically, DHIs include content (e.g. educational text, pictures and videos) and/or processes (e.g. games, mood trackers) that relate to the mental health problem being targeted. They can be accessed through different hardware (e.g. laptops, mobile phones, smartphones, wearables) and involve varied levels of interactivity. For example, MoodGym (a free publically-available cCBT course) is accessed online through a web browser and consists of five modules relating to 
understanding and managing depression and anxiety. Originally launched in 2001, MoodGym's content is delivered through an eLearning format consisting of text, images, animations, and interactive activities and quizzes (Christensen, Griffiths \& Korten, 2002). An example of a more recently developed DHI, FindMe (a publically-available app) is a game designed for children with autism to practice social skills, which can run on a tablet computer regardless of internet connectivity (Fletcher-Watson et al., 2015).

[Table 1 approximately here]

The number of DHIs aimed at CYP's mental health is growing rapidly (particularly mHealth apps) and outstrips the capacity of traditional randomised controlled trials (RCTs) to generate evidence of effectiveness. In 2015, mental health apps made up almost a third of disease-specific apps in app marketplaces (IMS Institute for Healthcare Informatics, 2015). As RCTs typically take five to seven years from initiation to reporting, this time frame is too slow to keep pace with the growth of DHIs. Given the continuing process of improvement and iterations in digital technology platforms and interfaces, it is likely that a DHI may be obsolete by the time a RCT is completed (Schueller, Muñoz \& Mohr, 2013). One possible solution to rationalising the requirement for RCTs for all DHIs is to apply the concept of 'substantial equivalence' as used for medical device and pharmaceutical regulation by the US FDA and similar regulatory bodies. Essentially, if a pivotal trial exists, DHIs meeting criteria for 'substantial equivalence' would not require further RCT evidence. For example, if a pivotal RCT (or meta-analysis) demonstrated effectiveness of a cCBT DHI for depression in CYP, then each subsequent version/iteration of a CCBT DHI for depression would not be required to demonstrate further RCT efficacy and safety evidence - but rather substantial equivalence to existing 'predicate' interventions (FDA U.S. Food \& Drug Administration, 2014). If substantial equivalence was established, then the relevant data to collect would then focus on usage, adherence, demographic access parameters, and user preferences (Murray et al., in press). 
129 Reviews of previous research have highlighted the disappointingly poor quality of RCTs of

130 DHIs. In particular, there are major difficulties combining and comparing trials in 131 systematic reviews and meta-analyses without clear specification of the DHI, including the 132 theoretical underpinning of the intervention, mode of digital delivery, level of therapist 133 input, and selection of intervention comparator. There have been attempts to standardise and improve reporting of trials in the field with an eHealth version of the Consolidated Standards of Reporting Trials statement ('CONSORT eHealth') (Eysenbach \& CONSORT eHealth Group, 2011). However, the uptake and impact of this and other reporting standards on the design and conduct of RCTs of DHIs remains to be established.

In addition to establishing the evidence-base for the clinical and cost-effectiveness of DHIs, we need better evidence on usability, acceptability and adherence with DHIs (i.e. do CYP actually want to use DHIs for mental health problems?), whether DHIs actually widen access, and how they should best be integrated into mental health services.

142 In this review we address the broad question of whether the promise and potential of DHIs

143 has been realised. Firstly, we review the evidence for the clinical and cost-effectiveness of 144 DHIs for mental health problems in CYP by conducting a synthesis of previous reviews and an updated systematic review of RCTs of DHIs in CYP (NCCMH, 2014; Pennant et al., 146 2015). Secondly, we identify and discuss the key research questions, methodological and 147 clinical issues related to the future development, evaluation and implementation of DHIs.

\section{METHODS}

\section{Meta-Review}

\section{Inclusion criteria}

151 We included scoping reviews, narrative reviews, systematic reviews, and meta-analyses 152 that focused on the evaluation of DHIs for improving mental health outcomes in CYP. 153 Reviews of interventions (e.g. CBT, self-help) that were adapted for digital delivery (e.g. 154 CCBT as an adaptation of FtF CBT) were included if they reported analyses relating to the digital version of the intervention and included $\geq 2$ studies. Reviews that reported results 
156 for adults were included if they separately reported analyses/findings for CYP, and included

$157>2$ studies of DHIs in CYP. Included reviews had to be peer-reviewed and in English.

\section{Search strategy}

159 Two authors (BD and CF) devised the search strategy by collating MeSH terms and keywords reflecting: a) CYP (e.g. child, adolescent, young person); b) mental health disorders; c) DHIs (e.g. internet interventions, apps, eHealth); and d) the sub-types of review included in the meta-review. The search was run on eleven online databases (Allied and Complementary Medicine, Ovid, MEDLINE, PsychINFO, PsychARTICLES, Embase, PubMed, ASSIA, Cochrane Library, CINAHL, and Web of Science), and a limited keyword search was also performed on the JMIR Publications database. The search was performed between $16^{\text {th }}-19^{\text {th }}$ November 2015, with a cut-off publication date of November $1^{\text {st }} 2015$. Reference lists of included reviews were hand-searched for additional publications. Each review's eligibility was assessed by BD through screening citation titles, with uncertainties discussed with CF and full-texts accessed if necessary. The full search terms and process are available in Appendix 1.

\section{Data extraction and synthesis}

172 Data extraction was conducted by BD using a template to collate the review's methodology

173 (e.g. aim of review, date of search), focus (e.g. type of intervention, age-group, and type 174 of mental health problem), search findings (e.g. number of papers, information about 175 interventions in review), and synthesis of the findings (e.g. descriptive or quantitative 176 synthesis). The data were checked by CF for accuracy. The heterogeneity of the included 177 reviews precluded a meta-analysis of the extracted data, and our findings are presented 178 as a systematic narrative review.

179 The AMSTAR tool was used to assess the methodological quality of systematic reviews and meta-analyses included in the meta-review (Shea et al., 2007). This tool is an 11-item

181 checklist of questions to appraise review quality: a 'yes' response is given a score of one, with 'no', 'can't answer' and 'not applicable' responses given scores of zero. This results in 
183

184

185

186

187

188

189

190

191

192

193

194

195

196

197

198

199

200

201

202

203

204

205

206

207

208

209

scores that range from 0 -to-11, with three categories of methodological quality: $0-4$ indicate 'low' quality, 5-8 'moderate' quality, and 9-11 'high' quality. Following guidance from a previous meta-review (Joyce et al., 2015), an alternate categorisation system was used for systematic reviews without a meta-analysis: 0-3 indicated 'low' quality, 4-7 'moderate', and 8-9 as 'high' quality. Each included review was assessed independently by $\mathrm{BD}$ and $\mathrm{CF}$, with any disagreements discussed to reach consensus.

\section{Systematic review}

\section{Search strategy}

Our review updated a previous systematic review, using the same inclusion/exclusion criteria, search protocol and methodology as NCCMH (2014) and Pennant et al (2015) (NCCMH, 2014). To be included in the review, participants had to be aged $<25$ years. Studies that included participants aged $\geq 18$ yrs were included if either a) the sample's mean age was $\leq 18$ years, or $b$ ) all participants were aged $\leq 25$ years. Additional keywords were added to the search to include recent technological developments in eHealth (e.g. apps, ecological momentary assessment, virtual reality and wearable devices). The updated search identified papers published from June 2013 to December $31^{\text {st }} 2015$. The full search protocol and terms are available in Appendices 2 and 3.

\section{Study selection and data extraction}

Citations from the search were screened for eligibility by CF and categorised as either 'eligible' or 'potentially eligible'. All 'potentially eligible' citations were read in full by CF and BD to identify whether they met full inclusion criteria, with any uncertainties discussed. Data extraction for eligible studies was conducted by CF and BD using a template. This included information about study design (e.g. number of trial arms), the target condition, main intervention evaluated (e.g. theoretical approach, type of technology used to deliver intervention, location of delivery, level of human/therapist support), inclusion/exclusion criteria, type of comparator, sample size, number of participants in each trial arm, participant characteristics (e.g. age, gender, baseline 
210 symptomology), primary and secondary outcome measures, fidelity and adherence

211 measures, key findings, and reporting of adverse events.

\section{RESULTS}

\section{Findings from search: Meta review}

214 A total of 1678 citations were identified through the search. After screening each citation's 215 title, 105 were identified as potentially eligible and the abstract read. The full texts of 37 articles were reviewed and 21 selected for inclusion. Figure 1 depicts the search process.

218 The 21 reviews consisted of two scoping reviews (Boydell et al., 2014; Seko, Kidd, Wiljer 219 \& McKenzie, 2014), 12 systematic reviews (Ali, Farrer, Gulliver \& Griffiths, 2015; Calear \& Christensen, 2010; Clarke, Kuosmanen \& Barry, 2015; Farrer et al., 2013; Fleming, et al., 221 2014; Hailey, Roine \& Ohinmaa, 2008; Reyes-Portillo et al., 2014; Rice et al., 2014; 222 Richardson, Stallard \& Velleman, 2010; Rickwood \& Bradford, 2012; Schlegl, Burger, Schmidt, Herbst \& Voderholzer, 2015; Siemer, Fogel \& Van Voorhees, 2011), two metaanalyses (Ebert et al., 2015; Podina, Mogoase, David, Szentagotai \& Dobrean, 2015), and five combined systematic reviews and meta-analyses (Davies, Morriss \& Glazebrook, 2014; Newton \& Ciliska, 2006; Pennant, et al., 2015; Rooksby, Elouafkaoui, Humphris, Clarkson \& Freeman, 2015; Ye et al., 2014).

The 21 reviews contained a total of 190 papers focused on the evaluation of approx. 147 unique DHIs. Appendix 4 cross-tabulates the DHIs in the 21 reviews. The majority of the reviews were focused on the clinical effectiveness of DHIs, in particular CCBT (including electronically-delivered CBT and internet-delivered CBT; see Table 1.), for anxiety and depression. The reviews are summarised in Table 2.

\section{Methodological quality of included reviews}

234 Two included reviews used a scoping methodology and so were not included in the AMSTAR rating (Boydell, et al., 2014; Seko, et al., 2014). Using the AMSTAR checklist, the majority 
of systematic reviews $(\mathrm{N}=9)$ and all reviews with meta-analyses $(\mathrm{N}=9)$ were rated as having 'moderate' methodological quality. Of the remaining systematic reviews, two were rated 'low' and one as being 'high' quality. Nine reviews explicitly stated that they included grey and unpublished literature in their review (Ali, et al., 2015; Calear \& Christensen, 2010; Clarke, et al., 2015; Farrer, et al., 2013; Newton \& Ciliska, 2006; Podina, et al., 2015; Richardson, et al., 2010; Rickwood \& Bradford, 2012; Ye, et al., 2014). Five reviews commented on the proportion of included studies that used intention-to-treat (ITT) analyses (Ali, et al., 2015; Davies, et al., 2014; Ebert, et al., 2015; Farrer, et al., 2013; Rooksby, et al., 2015). In the two meta-analyses of cCBT for anxiety and/or depression, inspections and analyses of funnel plots suggested some possible publication bias (Arnold et al., 2013; Ebert, et al., 2015; Podina, et al., 2015), while Davies et al's (2014) review of computer and web-based interventions did not appear to find unusual symmetry in funnel plots. Using the trim-and-fill procedures, Podina et al. (2015) found no evidence of publication bias in six studies with cCBT-waitlist comparisons, but one study (out of four) using a cCBT versus FtF CBT comparison design showed a higher-than-expected effect size that did not significantly change the meta-analytic findings. Using the same procedure, Ebert et al (2015) found that adjusting for missing studies did not result in significant changes upon meta-analysis findings.

\section{Findings from search: Systematic review}

Our updated search identified 5291 citations, reduced to 3748 after removing duplicates. 120 were identified as potentially eligible and their full-texts read. Thirty-one publications met inclusion criteria: two were from the same trial, resulting in 30 unique RCTs. These trials evaluated DHIs aimed at improving outcomes in attention deficit/hyperactivity disorder $(A D H D)(N=10)$, autism spectrum disorders (ASD) $(N=3)$, psychosis $(N=1)$, anxiety $(\mathrm{N}=4)$, depression ( $\mathrm{N}=6)$, anxiety and depression $(\mathrm{N}=3)$, eating disorders $(\mathrm{N}=2)$, and post-traumatic stress disorder (PTSD) and depression $(\mathrm{N}=1)$. Figure 2 illustrates this process. A total of 5273 participants $(M=175.7, M d n=89)$ were randomised across the 30 
263 studies. Table 3 provides a summary of included studies, including the numbers of 264 dropouts in each study. Unless otherwise stated, study results are from ITT analyses.

265 [Figure 2 approximately here]

266 [Table 2 approximately here]

267 [Table 3 approximately here]

268

269 Clinical outcomes

270 Anxiety and depression

271 Meta-review findings

272 Twelve reviews focused on anxiety and/or depression, predominantly with modularised

273 cCBT interventions compared to either inactive (e.g. waitlist, no treatment) or active non-

274 therapeutic (e.g. attention) controls.

275 Six reviews included meta-analyses of anxiety and/or depression outcomes (Davies, et al., 276 2014; Ebert, et al., 2015; Pennant, et al., 2015; Podina, et al., 2015; Ye, et al., 2014), 277 predominantly comparing the experimental intervention to 'non-active' or 'non278 therapeutic' controls (e.g. waitlist, placebo). Meta-analyses found support for the 279 effectiveness of CCBT in CYP with small-to-moderate effects ( $g=.16$ to .62) on depression 280 outcomes, and moderate-to-large effects ( $\mathrm{g}=.53$ to 1.41$)$ for cCBT targeting anxiety. 281 Heterogeneity varied considerably across analyses ( $\mathrm{I}^{2}$ range: $0 \%$ to $92.6 \%$ ). One review 282 found CCBT interventions were effective for anxiety outcomes in adolescents and young 283 adults (age 12-25 years) but not in children (age 5-11 years) (Pennant, et al., 2015). 284 Analyses comparing CCBT to an active comparator failed to show superiority of DHIs for 285 anxiety and depression outcomes (Davies, et al., 2014; Ye, et al., 2014), while Pennant 286 et al.'s (2015) analysis of two trials supported superiority of FtF CBT over cCBT. Through 287 the use of an evidence-base level criteria tool to classify interventions into different 
categories of efficacy, Reyes-Portillo et al. (2014) suggests the evidence for effectiveness is strongest for BRAVE-Online and categorises it as a 'probably efficacious' DHI.

Two reviews that compared non-cCBT DHIs (e.g. problem-solving therapy, cognitive bias modification) for anxiety and/or depression found that these interventions had mixed or uncertain effects (Pennant, et al., 2015; Reyes-Portillo, et al., 2014), with meta-analyses failing to demonstrate superiority of non-cCBT DHIs (Pennant, et al., 2015).

In looking at whether parents were involved in the DHI delivery, Podina et al. (2015) comment that as the majority (five out of six) of studies using a CCBT-waitlist comparison involved a degree of parental support, it would suggest that parents are needed in order for the intervention to produce positive outcomes. In their meta-analysis of CCBT for depression and anxiety in CYP, Ebert et al. (2015) classified interventions by their level of parental involvement: parents were involved in six (out of 13) studies. Parental involvement was not found to be associated with effect sizes ( $g=0.64$, compared to $g=0.83$ in studies with no parental involvement), suggesting that parental support may not be needed to see positive results. Parental involvement may be particularly needed with younger CYP to support engagement (i.e. starting and working with the intervention) (Pennant, et al., 2015).

Three reviews reported results separately for different age groups or reported on age as a moderating variable. The effects of DHIs on anxiety and depression outcomes were greater in adolescents and young adults than in children (Ebert, et al., 2015; Pennant, et al., 2015; Podina, et al., 2015). A meta-analysis combining both anxiety and depression outcomes Ebert et al. (2015) found a larger effect size $(g=0.95)$ with adolescents (aged $\geq 13$ years), compared with children (aged $\leq 12$ years, $g=0.51$ ) and studies combining adolescents and children $(\mathrm{g}=0.48)$. Pennant et al. (2015) found effects for anxiety cCBT interventions to be greater for young people aged 18-25 years than young people aged 12-17 yrs. However, the 18 to 25 year olds also had higher baseline anxiety scores which may account for larger effects. 


\section{Systematic review findings}

317 Almost half of the 30 RCTs evaluated DHIs for depression $(N=6)$, anxiety $(N=4)$, or both 318 depression and anxiety $(\mathrm{N}=4)$.

\section{i. Depression}

Six RCTs evaluated DHIs for depression (Kramer, Conijn, Oijevaar \& Riper, 2014; Lillevoll, Vangberg, Griffiths, Waterloo \& Eisemann, 2014; Saulsberry et al., 2013; Smith et al., 2015; Stasiak, Hatcher, Frampton \& Merry Sally, 2014; Yang, Ding, Dai, Peng \& Zhang John, 2014). Three DHIs used cCBT (MoodGym, StressBusters, and The Journey) (Lillevoll, et al., 2014; Smith, et al., 2015; Stasiak, et al., 2014); one DHI (Project CATCH-IT) incorporated behavioural activation, CBT, interpersonal psychotherapy, and community resiliency concept model (Saulsberry, et al., 2013); one DHI delivered one-to-one chatroom-based Solution-Focused Brief Therapy (SFBT) (PratenOnline) (Kramer, et al., 2014); and one DHI used computer-based attention bias modification (ABM) training (Yang, et al., 2014). 1345 participants were included in the six depression trials, with sample sizes ranging from 34 to $775(M=224, M d n=98)$. Studies targeted adolescents and young adults, ranging from 12 to 22 years old $(M=17.6, M d n=17.3)$. At post-intervention assessment, attrition ranged from 0\% (Yang, et al., 2014) to 42.2\% (Kramer, et al., 2014) ( $M=16 \%, M d n=11.5 \%)$. Lillevoll et al. (2014) found substantial non-participation from the MoodGYM intervention, with only $8.5 \%$ (45/527) participants logging on, and few proceeding beyond the first part of the programme. Unlike the other included RCTs, Lillevoll et al. (2014) had a naturalistic design that did not control or monitor the location where the intervention was accessed. Although participants were randomised to receive one of three types of email-reminder (plus a waitlist control group), it was their own choice to create a MoodGYM user account to access and use the online intervention. 
depression (Saulsberry, et al., 2013). One trial was a population-based intervention, where elevated baseline depressive symptoms were not an inclusion criterion (Lillevoll, et al., 2014). Severe depressive symptomology, or a diagnosis of major depression, were exclusion criteria for five studies. Two of the studies involved interventions accessed at school (Smith, et al., 2015; Stasiak, et al., 2014); three evaluated interventions accessed at a time and location chosen by the young person (Kramer, et al., 2014; Lillevoll, et al., 2014; Saulsberry, et al., 2013); and one was accessed in a laboratory setting (Yang, et al., 2014).

The level of human and technical support provided to participants varied greatly between DHIs. The RCT of MoodGym involved three trial arms: one condition received no prompts (i.e. completely unguided), while the other two arms received automated emails which were either tailored or untailored to participants' baseline data (Lillevoll, et al., 2014). Project CATCH-IT was delivered in conjunction with a one-off FtF meeting with a primary care physician (Saulsberry, et al., 2013). Adolescents received The Journey cCBT intervention within school time with "minimal oversight from school counsellors" (Stasiak, et al., 2014). PratenOnline provided online chat-based SFBT that involved secure, one-toone, synchronous remote live therapy (Kramer, et al., 2014). Two studies did not specify support provided with the DHIs (Smith, et al., 2015; Yang, et al., 2014).

These recent studies were associated with greater pre-post improvements in depression outcomes, compared to: waitlist control (Kramer, et al., 2014; Smith, et al., 2015); no intervention (Yang, et al., 2014); a computer-delivered psychoeducational program (Stasiak, et al., 2014); a placebo version of ABM training (Yang, et al., 2014); and a group who received the same Project CATCH-IT DHI but with briefer FtF advice from practitioners (Saulsberry, et al., 2013). Additionally, Project CATCH-IT reduced hopelessness and selfharming thoughts (Saulsberry, et al., 2013), while computer-based ABM training had no effects on ruminations (Yang, et al., 2014). As a result of low-take up of MoodGym, Lillevoll et al. (2014) performed 'users vs. non-users' analyses but failed to find any significant intervention effects for depressive symptoms and did not perform ITT analysis. 
370 Four trials reported post-intervention follow up data extending from 3 to 12 months

371 (Kramer, et al., 2014; Saulsberry, et al., 2013; Smith, et al., 2015; Yang, et al., 2014).

372 Over a quarter (28.2\%) of young people receiving PratenOnline maintained clinically-

373

374

375

376

377 significant change at 4.5 month follow-up, compared to waitlist controls (11.4\%) (Kramer, et al., 2014). Improvements found at 6-weeks post-intervention were sustained and increased in both intervention groups at one year follow-up for Project CATCH-IT (Saulsberry, et al., 2013). Adolescents who used StressBusters self-reported improvements in depression and anxiety from post-intervention to 3-month follow-up, but not at 6-month follow-up (Smith, et al., 2015). This study did not perform ITT analysis. For university students participating in lab-based $A B M$ training, post-intervention reductions in depressive symptomology were maintained at 3 and 7-month follow-up, but there were no between-group differences at 7-month follow-up (Yang, et al., 2014).

\section{ii. Anxiety}

Four RCTs evaluated DHIs for anxiety (Shechner et al., 2014; Sportel, Hullu, Jong \& Nauta, 2013; Storch et al., 2015; Vigerland et al., 2016). Two RCTs compared cCBT to treatmentas-usual (TAU) (any psychotherapy and/or medication; Storch, et al., 2015) or waitlist (Vigerland, et al., 2016); one compared ABM training plus CBT, to attention placebo plus CBT, and FtF CBT alone (Shechner, et al., 2014); and one compared cognitive bias modification (CBM) training to in-class group CBT and no-treatment control (Sportel, et al., 2013). Participants in all four of the RCTs were recruited on the basis of having a diagnosis of an anxiety disorder (Shechner, et al., 2014; Storch, et al., 2015; Vigerland, et al., 2016), or meeting the threshold for high-levels of social anxiety and/or test anxiety (Sportel, et al., 2013). A total of 496 participants were included, with sample size ranging from 63 to $240(M=124, M d n=96.5)$. Studies included both children and adolescents (range 6 to 18 years), with a mean age range of 9.8 to 14 years $(M=11.3$ yrs, $M d n=10.7$ yrs). Attrition at follow-up ranged from $15.3 \%$ to $51.1 \%$. Participants completed the intervention at a variety of locations: home (Sportel, et al., 2013; Vigerland, et al., 2016), a community health centre (Storch, et al., 2015) or hospital (Shechner, et al., 2014). 
CCBT was associated with significant improvements in anxiety post-intervention and at follow-up, compared to waitlist (Vigerland, et al., 2016) and TAU groups (Storch, et al., 2015; Vigerland, et al., 2016). However, Vigerland et al. (2016) did not perform ITT analysis. The augmentation of FtF CBT with computer-based ABM training significantly decreased the frequency of parent and child-rated anxiety symptoms compared to FtF CBT alone (Shechner, et al., 2014). A home-based trial of online CBM training found a significant reduction in social phobia and anxiety scores for both online intervention and group CBT arms compared to no treatment, with post-treatment effects at 6 month followup largest for the group CBT intervention (Sportel, et al., 2013).

\section{iii. Anxiety and Depression}

Four studies evaluated DHIs targeting both anxiety and depression: three evaluated a CCBT intervention (Melnyk et al., 2015; Sethi, 2013; Wong, Kady, Mewton, Sunderland \& Andrews, 2014); the other evaluated a multi-theoretical intervention incorporating motivational-enhancement, cognitive behavioural strategies and behavioural principles (Ruggiero et al., 2015). A total of 2173 participants were recruited to these trials; age range $12-25$ years, $(M=17.9, M d n=18.5)$. Participants were recruited with mild-tomoderate anxiety symptoms and/or depression symptoms (Sethi, 2013), or because they lived in an area which had experienced a significant natural disaster (Ruggiero, et al., 2015). Participants completed the intervention in school (Wong, et al., 2014), or in a community centre or on university campus (Sethi, 2013). The other two interventions were delivered online without specifying a location (Melnyk, et al., 2015; Ruggiero, et al., 2015).

The findings for the three cCBT interventions were mixed. In a four-arm trial, Sethi (2013) found the three experimental groups (MoodGym-only, FtF CBT-only, and combination of MoodGym and FtF CBT) reported improvements in depression and anxiety symptoms, but the group who received MoodGym combined with FtF CBT reported the greatest reduction in anxiety symptoms. Melnyk et al. (2015) found that the intervention significantly reduced anxiety but only for those with elevated levels at baseline. However, this study did not 
426 perform ITT analysis. In the trial of ThisWayUp (Wong, et al., 2014), participants who

427 received the depression-focussed modules had reduced anxiety and depression scores, 428 while those who received the anxiety-focussed modules only improved with anxiety symptoms. ThisWayUp involves FtF group discussions and worksheets to consolidate 430 learning, and so constitutes a 'blended' online and FtF intervention. Evaluation of COPE 431 (Creating Opportunities for Personal Empowerment) found no post-intervention 432 differences for anxiety and depression symptoms between the intervention and no-access 433 control (Melnyk, et al., 2015). Finally, a multi-theoretical online intervention (Bounce Back Now) for adolescents affected by natural disaster resulted in improvements in PTSD and depressive symptoms at 12-month follow up (Ruggiero, et al., 2015).

\section{Summary: DHIs for anxiety and depression}

Depression and anxiety were the most common clinical targets for DHIs in both the metareview and systematic-review. DHIs most frequently cited were MoodGym, BRAVE-Online, Project CATCH-IT, Master Your Mood Online (Grip Op Je Dip) and MobileType. Except for MobileType, these DHIs all provide web-delivered module-based cCBT. While these modularised CCBT DHIs follow the traditional 'sessional' approach to CBT therapy, they are somewhat limited in that they require a sit-down approach to treatment and fail to fully exploit the ubiquitous nature of modern digital technologies. For example, mobile technology (e.g. smartphones, wearables) can accommodate different styles of delivery, learning and collection of patient-centred outcomes, such as ecological momentary sampling and instant access to crisis management strategies. MobileType is a mobile phone-delivered intervention which uses a momentary sampling approach to remotely assess participants' mood, stress, current activity and alcohol and cannabis use within their natural environment (Kauer, Reid, Sanci \& Patton, 2009). While mood monitoring is not therapeutic in its own right, these extra activities could potentially improve the personalisation of the intervention and support adherence. Increasingly, remote active and passive monitoring of mood are being integrated with therapeutic interventions. Hence, 
453 the distinction between mHealth digital monitoring and interventions is likely to become

454 increasingly blurred.

455 Overall, the strongest evidence of clinical effectiveness comes from DHIs using a cCBT

456

457

458

459

460

461

462

463

464

465

466

467

468

469

470

471

472

473

474

475

476

477

478

479 approach, with weaker evidence for the effectiveness of non-CBT DHIs. The largest effects for DHIs are reported in RCTs with: a) non-active comparators (e.g. waitlist control) vs. active comparators (TAU or attention control), b) interventions targeting older adolescents and young adults vs. children, and c) facilitated therapist-guided support vs. self-guided intervention. Most trials recruited participants with mild to moderate clinical symptoms and excluded young people with severe depression or high suicidal risk. Uptake and adherence was particularly poor for self-guided interventions such as MoodGYM that included automated prompts but no human support. No studies provided data on costeffectiveness of DHIs.

\section{Eating disorders}

\section{Meta review findings}

Two reviews evaluated DHIs for treating and preventing eating disorders (EDs) (Newton \& Ciliska, 2006; Schlegl, et al., 2015). Newton and Ciliska (2006)reported findings from five trials of Student Bodies, an online self-guided intervention including psychoeducational, social learning theory and cognitive behavioural approaches. Four trials were conducted with American undergraduate university students with a mean age range of 19.3 - 20 years; the other trial was a quasi-experimental study with high school students ( $M=15$ years). Meta-analysis found no significant benefit of Student Bodies at post-intervention, or at follow-up, for ED-related attitudes, behaviours, or body satisfaction. In a systematic review of technological interventions for EDs, Schlegel et al. (2015) report findings from three studies with adolescents: two CCBT programmes with weekly therapist email support (SALUD BN and Overcoming Bulimia Online) were effective in reducing binging, vomiting and ED psychopathology at post-intervention and follow-up. The additional intervention (My Body, My Life), which was facilitated by weekly online 
480

481

482

483

484

485

486

487

488

489

490

491

492

493

494

495

496

497

498

499

500

501

502

503

504

505

506

group sessions with a therapist, showed moderate pre-post improvements in perceived body image. Two other reviews report findings from DHIs for EDs (Ali, et al., 2015; Siemer, et al., 2011). Ali et al. (2015) suggested the inclusion of peer support in Student Bodies had little effect on ED-related attitudes.

\section{Systematic Review}

Findings from the updated review found low quality evidence of equivalence between the Student Bodies intervention and waitlist control for ED symptomology (e.g. binging, purging, restrictive eating) and weight concerns (NCCMH, 2014). We identified two further RCTs of Student Bodies in female university students ( $N=216$, aged $18-25$ years) who were either at high-risk or met criteria for subclinical EDs. Saekow et al. (2015) found no differences (ITT analysis) between intervention and waitlist control for ED symptomology, weight concern and psychosocial functioning, although significant improvements in these measures were found with a non-ITT analysis of those who completed the entire intervention. Kass et al. (2014) found participants using Student Bodies with access to the online discussion group had significantly lower weight concern scores than those without the group discussion feature, but no differences were found for ED symptomology.

\section{ADHD}

None of the 20 included reviews assessed the effectiveness of DHIs for ADHD in CYP. We identified 10 RCTs for the updated systematic review that evaluated computer-based cognitive training interventions aimed at improving ADHD-related symptoms and behaviours. Interventions included: electroencephalogram (EEG) based neurofeedback training (NFT) (N=2) (Arnold, et al., 2013; Dongen-Boomsma, Vollebregt, Slaats-Willemse \& Buitelaar, 2013); NFT augmenting TAU ( $\mathrm{N}=2$ ) (Bink, van Nieuwenhuizen, Popma, Bongers \& van Boxtel, 2015; Bink, Van Nieuwenhuizen, Popma, Bongers \& Van Boxtel, 2014; Steiner, Frenette, Rene, Brennan \& Perrin, 2014); NFT with medication (N=1) (Li, Yang, Zhuo \& Wang, 2013); working memory training (WMT) $(\mathrm{N}=3)$ (Chacko et al., 2014; Dongen-Boomsma, Vollebregt, Buitelaar \& Slaats-Willemse, 2014; Egeland, Aarlien \& 
507 Saunes, 2013); executive functioning training (EFT) $(\mathrm{N}=1)$ (Dovis, Oord, Wiers \& Prins,

508 2015); or treatment delivered via videoconferencing $(\mathrm{N}=1)$ (Myers, Vander Stoep, Zhou, 509 McCarty \& Katon, 2015). All studies involved participants with ADHD (N=9) or who met 510 criteria for possible ADHD (Myers, et al., 2015). Comparators included; placebo ( $N=7$ ), 511 TAU $(\mathrm{N}=1)$, a partially active intervention $(\mathrm{N}=1)$, waitlist control and TAU $(\mathrm{N}=1)$, placebo 512 and medication ( $\mathrm{N}=1)$, and a cognitive training program $(\mathrm{N}=1)$. All placebo conditions 513 involved a program that was identical to the experimental intervention but non-adaptive 514 (e.g. it did not increase in difficulty as performance improved). All trials included as a 515 primary outcome measure parent and/or parent, caregiver or teacher-rated ADHD 516 symptoms.

517 The majority of trials recruited children ( $M=9.98$ yrs, $M d n=9.82)$, with seven including 518 only children aged $\leq 12$ years. 861 participants were randomised, with sample sizes 519 ranging from 39 to $223(M=86, M d n 80)$. Reported attrition was small across all studies. 520 Three studies delivered the intervention at home (Chacko, et al., 2014; Dongen-Boomsma, 521 et al., 2014; Dovis, et al., 2015), one in a clinic (Dongen-Boomsma, et al., 2013) and two 522 in school (Egeland, et al., 2013; Steiner, et al., 2014). Excluding the RCT evaluating a 523 videoconferencing service (Myers, et al., 2015), seven studies included in-person or 524 telephone-based support from a training aide (e.g. parent, guardian, teacher; $\mathrm{N}=2$ ) or a 525 professional (e.g. certified coach, therapist, research assistant; $N=5$ ). The other two trials 526 failed to report whether support was provided (Arnold, et al., 2013; Li, et al., 2013).

527 EEG-based neurofeedback training (NFT) aims to improve ADHD symptoms through 528 training designed to suppress EEG theta wave activity and increase beta wave activity. All 529 four RCTs of NFT report mixed findings for effectiveness. Two studies found that both the 530 NFT and attention placebo groups reported pre-post improvements in parent and/or 531 investigator and/or teacher-rated ADHD symptoms, but there were no differences between 532 the two groups (Arnold, et al., 2013; Dongen-Boomsma, et al., 2013) and the study by 533 Arnold et al. (2013) did not perform ITT analysis. CYP who received NFT in addition to 534 methylphenidate medication showed significant improvements in parent-rated ADHD 
535

536

537

538

539

540

541

542

543

544

545

546

547

548

549

550

551

552

553

554

555

556

557

558

559

560

561

562

symptoms and social functioning, compared to a control group who received attention placebo plus methylphenidate medication ( $\mathrm{Li}$, et al., 2013). However, this study did not perform ITT analysis. Finally in comparison to children who received a cognitive training intervention, children who received the NFT intervention reported better parent-reported executive functioning, behaviour regulation and metacognition outcomes, and teacherreported attention and inattention outcomes (Stangier, 2016).

Working memory training (WMT) and executive functioning training (EFT) aim to improve specific or wider deficits in cognitive functioning and attentional skills (Melby-Lervåg \& Hulme, 2012). The three RCTs of WMT report contrasting results. Chacko et al. (2014) found that WMT participants showed greater improvements in verbal and nonverbal memory compared to attention placebo, with both groups reporting pre-post improvements in parent-reported ADHD symptoms, but no differences between the two groups. Egeland et al. (2013) reported no changes over time or between the WMT and waitlist groups in parent and teacher-rated ADHD symptoms, but the WMT group did report improved mathematics and reading skills. Egeland et al. (2013), however, did not perform ITT analysis. Finally, Dongen-Boomsma et al (2014) found the WMT group showed significantly greater improvements than attention placebo in one verbal working memory task, and while both groups reported improvements over time in parent and teacher-rated ADHD symptoms, there were no statistically significant differences between the groups. However, again, this study did not perform ITT analysis. An intervention targeting multiple aspects of executive functioning found ADHD symptoms improved over time regardless of the intervention received (Dovis, et al., 2015). A trial of a videoconferencing telehealth service for remote treatment of ADHD showed that both the videoconferencing and control service improved teacher and caregiver-rated ADHD symptoms, with greater improvement in the intervention group (Myers, et al., 2015).

\section{Summary: DHIs for ADHD}

Computerised cognitive 'brain training' programmes for ADHD include WMT, EFT and EEG NFT. To date, the results of trials have been inconsistent, with no overall differences 
563

564

565

566

567

568

569

570

571

572

573

574

575

576

577

578

579

580

581

582

583

584

585

586

587

588

589

590

reported between DHIs and active placebo interventions. The negative NFT findings align with recent meta-analyses suggesting that NFT cannot be currently recommended as treatment for ADHD (Cortese et al., 2016). In previous reviews, the largest effects for non-pharmacological interventions on ADHD symptoms were found for outcomes reported by parents who may be 'unblinded' to intervention allocation where there are non-active comparators. Similarly, in our review treatment effects of DHIs are attenuated or non-significant for ADHD outcomes reported by independent observers (e.g. teachers), who are more likely to be 'blinded' to intervention allocation (Cortese et al., 2015). Given that face to face non-pharmacological interventions for ADHD have not demonstrated efficacy, it is perhaps not surprising that digital versions would also not be effective. In summary, the results of the updated systematic review suggest that DHIs (including WMT, EFT and EEG NFT) cannot be recommended for the treatment of ADHD.

\section{Autism Spectrum Disorders (ASD)}

Only one review identified a study of a DHI for CYP with ASD (Jang et al. 2012, cited in Boydell et al., 2014): their evaluation of an eLearning training intervention for family members of children with ASD found those who received the intervention reported greater improvements in skills and knowledge relating to applied behaviour analysis.

We identified three RCTs of DHIs for CYP targeting ASD symptoms/ impairments: a mobile phone 'app' for practising and improving communication skills (FindMe) (FindMe; FletcherWatson et al., 2013); an interactive software program to improve recognition of emotion in facial and vocal expressions (MindReading) (MindReading; Thomeer et al., 2015) and a computer-based program to improve working memory (WM) and cognitive flexibility (CF) (Braingame Brian) (Vries, Prins, Schmand \& Geurts, 2015) $(\mathrm{N}=218$, M age 7.8 yrs). Findings from these studies are mixed. Fletcher-Watson et al. (2015) reported no differences between experimental (FindMe) and waitlist and TAU combined groups for ASD symptoms at post-intervention and follow-up, although parents gave positive feedback about their child's enjoyment of the intervention. Compared to waitlist control, those who used the MindReading program showed significant improvements with a large effect size 
591 in social functioning, face and voice recognition at post-treatment and at 5-week follow592 up (Thomeer, et al., 2015). However, this study did not perform ITT analysis. All participants using Braingame Brian improved in WM, CF, attention, social functioning,

594 quality of life and ADHD-related behaviour (Vries, et al., 2015).

\section{Summary: DHIs for ASD}

596 DHIs for CYP with ASD are designed primarily for pre-adolescent children and often 597 incorporate computer game-based formats aimed at training and improving core deficits 598 in social understanding, empathy, and emotional recognition. While these games appear 599 popular (particularly with parents) the results of trials have failed to show consistent 600 benefits that transfer outside the specific context of the game to affect core ASD 601 symptoms and deficits. Less attention has been given to DHIs which target associated 602 symptoms and behaviours in ASD such as anxiety and challenging behaviour. Given that

603 these symptoms may be more amenable to intervention than core deficits of ASD, and 604 trials are emerging show that these interventions work FtF, digital adaptations would be 605 welcome.

\section{Psychosis}

None of the 21 included reviews assessed the clinical effectiveness of DHIs for psychosis in CYP. Our systematic review identified one study of Captain's Log, a computer-assisted cognitive remediation (CACR) program for adolescents with, or at risk of, psychosis

610 (Urben, Pihet, Jaugey, Halfon \& Holzer, 2012). This intervention aims to train attention, 611 concentration, memory, and visuo-spatial and visuo-motor skills. Post-intervention, both 612 experimental and placebo control groups reported a significant improvement in attention, memory processing, general psychopathology and social functioning, with the intervention

614 group reporting significantly greater improvement in visuospatial abilities compared to 615 control (Holzer et al., 2014). However, there were no differences in WM, executive 616 functioning, psychotic symptoms and psychosocial functioning at 9-week and 6-month 617 follow up. 


\section{Meta review findings}

620 Two reviews examined the effects of tele-psychiatry or tele-medicine for CYP (Boydell, et 621 al., 2014; Hailey, et al., 2008) with telecommunication technology (e.g. telephone, 622 videoconferencing) used to either deliver mental health treatment or to remotely diagnose mental health disorders. Descriptive reviews suggest that delivering remote services via

624 telephone and video-conferencing is acceptable to healthcare practitioners, CYP, and their 625 families. However, studies to date have failed to report the impact on service access for 626 'hard to reach' groups, treatment adherence and clinical effectiveness, suggesting an

627 important gap in the research literature.

\section{Systematic review findings}

629 Myers et al. (2015) evaluated a videoconferencing intervention delivering six sessions of 630 pharmacotherapy and in-person caregiver behaviour training for children with ADHD. Both the videoconferencing group and control group (who received only one videoconferencing consultation) reported improvements in teacher and caregiver-rated ADHD symptoms, with the intervention group (who received more clinical contact) reporting significantly greater improvement. Unlike DHIs designed as interventions for specific conditions, telepsychiatry/tele-medicine refers to a generic telecommunications platform used to deliver remote assessment, monitoring and treatment by healthcare professionals across a range of conditions and interventions. Overall, remote videoconferencing appears acceptable to those recruited into studies. However, there is a notable lack of evidence of cost-

639 effectiveness and whether this technology increases access to services for previously 640 excluded groups.

\section{Experience of using DHIs: Eliciting views of young people and parents}

642 We identified nine studies that explicitly sought participants' feedback about their 643 experience and satisfaction with the DHI, either through administering a quantitative 644 survey and/or a qualitative approach. Feedback about satisfaction was gained from the 
645 CYP participants (Melnyk, et al., 2015; Saekow, et al., 2015; Stasiak, et al., 2014), the

646 CYP participant and their parents (Arnold, et al., 2013; Storch, et al., 2015; Thomeer, et 647 al., 2015; Vigerland, et al., 2016), or from the CYP's parents only (Fletcher-Watson, et al., 648 2015; Steiner, et al., 2014). CYP and parents reported moderate-to-high satisfaction with 649 the DHIs (Arnold, et al., 2013; Stasiak, et al., 2014; Storch, et al., 2015; Thomeer, et al., 650 2015; Vigerland, et al., 2016), with qualitative feedback being generally positive about 651 the DHI and its potential to help with mental health and wellbeing, and also provided 652 suggestions for future improvements in designing DHIs (Fletcher-Watson, et al., 2015; 653 Melnyk, et al., 2015; Saekow, et al., 2015; Stasiak, et al., 2014).

654 Adherence to DHIs and association with outcome

655 None of the studies in the meta-review addressed issues around dose response, such as 656 how much of the intervention is needed to produce beneficial outcomes. Given the current 657 challenges of the field (e.g. difficulties with establishing a DHI taxonomy), it is still difficult 658 to know exactly what amounts to an appropriate (or 'minimum effective') dose of an 659 intervention.

660 Similarly only four (out of 30 ) papers in the updated systematic review provided 661 information about the minimum effective 'dosage' of their DHI or levels of adherence. In 662 one trial of WMT for ADHD, a 'complier' meant the participant completed $\geq 20$ training 663 sessions (out of a possible 25 sessions) (Dongen-Boomsma, et al., 2014), while in a trial 664 of EFT for ADHD "compliers" were defined as those who completed all 25 training sessions 665 (Dovis, et al., 2015). Lillevoll et al. (2014) categorised level of adherence of MoodGym 666 into three categories: non-participation, one module only, and two or more modules. 667 Finally in the evaluation of a web-based intervention for disaster-affected adolescents and 668 their families, Ruggiero et al. (2015) defined a "completer" as a participant (adolescent or 669 parent) who completed $\geq 1$ intervention module.

670 Furthermore, seven studies reported associations between adherence/dosage and 671 outcomes. Four of these reported no associations between adherence or level of 
672 intervention completion and outcome (Ruggiero, et al., 2015; Saekow, et al., 2015;

673 Steiner, et al., 2014; Vigerland, et al., 2016). In one trial of WMT for ADHD, participants 674 who did not complete WMT were more likely to score higher on inattentive and 675 hyperactive/impulsive measures (Dongen-Boomsma, et al., 2014), while spending longer 676 amounts of time engaging with a CACR program for psychosis was associated with greater 677 gains in attention (Holzer, et al., 2014). Finally, findings from the evaluation of the FindMe 678 app for children with ASD found no associations between time spent engaging with the 679 app and autism-related behaviours, but a negative correlation between game play, visual 680 perception and motor scores was found upon removal of an outlier (Fletcher-Watson, et 681 al., 2015).

682

\section{DISCUSSION}

684 Our review of the effectiveness of DHIs has focused on evidence from RCTs, with the 685 majority conducted on CCBT targeting depression and anxiety in adolescents and young 686 adults, with far less research focused on other clinical areas and therapeutic approaches 687 or mobile enabled (mHealth) technologies.

688 Overall, there is some support for the role of cCBT in improving symptoms of depression 689 and anxiety in CYP. There is also evidence from 'head to head' trials that therapist-guided 690 (remote) cCBT is as effective as FtF CBT (Sethi, 2013). However, existing trials have 691 focused on older adolescents with mild/moderate symptomatology and, as a result, it is 692 still not clear whether DHIs are useful for CYP who present with more severe symptomatology typically found presenting to mental health services. Trials with active 694 comparators show less benefit of DHIs than those with non-active controls. There is some 695 evidence that human support, be that in the form of a therapist's guidance or researcher contact, may be beneficial in terms of adherence and effectiveness. DHIs for ADHD, ASD,

697 eating disorders, psychosis and PTSD show uncertain benefits. Importantly, there is a 698 notable lack of evidence concerning the cost-effectiveness of DHIs. 
699 Overall, the heterogeneity of DHIs and poor quality of many studies make it difficult to 700 draw definitive conclusions about the effectiveness of DHIs and the role they should play 701 in mental health services for CYP. Our review highlights a number of important research questions and methodological issues that need to be considered for the field to move 703 forward.

704 Research Priorities and Methodological Issues

\section{Obtaining evidence of cost-effectiveness}

706 There is a remarkable lack of data on the cost-effectiveness of DHIs in CYP. This is surprising given the promise that DHIs can increase health service efficiency through the ability to deliver effective interventions at scale with minimal incremental costs. Several of the reviews in our meta-review mention the limited information about cost-effectiveness or even how DHI costs compare to usual mental health care and treatment. Many DHI trials include some level of human support, but the costs of this compared to usual treatment is not known. Boydell et al. (2014) note that the widely held assumption that DHIs are more affordable and associated with lower costs, more ease of administration, and reduced therapist time has not been substantiated to date. There are several factors that influence the calculation of costs in delivering DHIs, such as where the $\mathrm{DHI}$ is delivered (e.g. 'internally' within mental health services) (Palmqvist, Carlbring \& Andersson, 2007), the associated level of support given to users, and who 'owns' the DHI. For example, some internet-delivered DHIs are commercialised and have to be bought in by individuals or health service providers, while others are free to use and are publically available (e.g. MoodGym) (Gilbody et al., 2015). We emphasise the need to consider sustainability and cost-effectiveness from the beginning of DHI development. The development phase for a DHI should include consideration of the long term costs of maintenance and updating, how these costs could be met, and who will take responsibility for them.

\section{The role of human support in DHIs}

725 A critical research question in the design, evaluation and implementation of DHIs relates to the use of human support and how this affects engagement with the intervention and clinical outcomes. Across trials of DHIs the level of human support or facilitation is poorly 
specified, which obscures the effect of human support on engagement/adherence and outcomes. Between different DHIs, the level of human support varies in terms of who is providing it (e.g. a trained layperson, parent, teacher or clinician), the degree of support provided (e.g. unguided, semi-guided, fully guided), its purpose (e.g. to provide encouragement, to check for technical issues, or augment therapy) and the uniqueness of the support (e.g. tailored support for one user or automated support to all users). These factors will all influence CYP's motivation and continued engagement with the intervention, and providing some sort of human or therapist support, even at a minimal level, has been previously identified as a significant moderating factor influencing therapeutic outcomes and engagement (Rickwood \& Bradford, 2012). This is important for policy because DHIs are often promoted, incorrectly in our view, as a low cost alternative to FtF services due to their automated delivery with very low or zero incremental costs.

Six adult-only studies found a positive relationship between adherence and receiving support during online interventions, with qualitative findings suggesting that participants were less likely to adhere if they had limited human contact (Beatty \& Binnion, 2016). Findings from 25 RCTs of mostly adult samples evaluating CCBT for depression show larger intervention effects as the degree of human contact increased: no therapist contact, $\mathrm{d}=.21$; contact before treatment only, $\mathrm{d}=.44$; contact during the treatment only, $\mathrm{d}=.58$; and contact before and during treatment, $d=.76$ (Johansson \& Andersson, 2012). However, meta-analyses of CCBT with CYP report mixed impact of support upon depression and anxiety outcomes (Farrer, et al., 2013; Pennant, et al., 2015; Podina, et al., 2015). Larger effect sizes were found for studies involving 'minimal' therapist input, compared to studies with 'significant' input in CCBT for anxiety (Podina, et al., 2015). Ebert et al. (2015) found a larger effect size in CCBT studies that had no parent involvement $(g=.83)$ compared to those with parent involvement $(g=.64)$. In evaluating various technologies upon mental health outcomes in university students, Farrer et al. (2013) found no association between outcomes and amount of human contact provided to participants. Hence, an important research question concerns the impact of human support on both 
756

757

758

759

760

761

762

763

764

765

766

767

768

769

770

771

772

773

774

775

776

777

778

779

780

781

782

adherence and outcome for DHIs in CYP and whether the effects differ (and if so, why) from the consistent findings reported in adults.

Young people have expressed a need for some level of support in receiving DHIs or to use it in conjunction with FtF therapy (Cheek et al., 2014; Mitchell \& Gordon, 2007; Pretorius, Rowlands, Ringwood \& Schmidt, 2010). Support may not have to be a 'real' person, but could be automated through the DHI itself. When asked about their 'ideal app' for managing their condition, young people and adults with ADHD highlighted the need for a virtual 'coach' or 'mentor' to provide support and encouragement (Simons et al., 2016). Developments in virtual reality, artificial intelligence and machine learning are creating 'virtual human' agents that, in the next generation of DHIs, could act as automated, interactive coaches to support personalised delivery of DHIs (Valstar et al., 2014).

\section{Choosing appropriate comparators}

The range of comparators used across trials of DHIs range from active digital and nondigital (e.g. attention control and FtF CBT) comparator interventions vs. non-active controls (e.g. waitlist). In general, effects are largest when DHIs are compared to nonactive controls, and differences are smallest when there is an active comparator.

The selection of a suitable comparator is determined by the research question addressed. In pragmatic trials that aim to determine the effectiveness of a new DHI compared to current best practice, the comparator is typically TAU. However, in trials of DHIs, the participants in the TAU group may have access to a range of other digital interventions that may be hard to prevent or track (e.g. online psychoeducational material), but risks undermining the results of the trial. In contrast, 'active' comparators control for nonspecific effects of the intervention package such as human support, attention and on-line usage. It is critical to understand if human support is important only for increasing engagement and adherence or is an active component in therapeutic change. If the latter is true, then an 'active' control with human support may obscure the true effect to the DHI. 
783

784

785

786

787

788

789

790

791

792

793

794

795

796

797

798

799

800

801

802

803

804

805

806

807

808

809

810

\section{Identifying active components of DHIs}

Understanding which components of a DHI actually have the predicted impact on the outcome, and whether and how components interact, is critical to DHI development and evaluation. Most DHIs are highly complex, containing multiple components, so the development process needs to include a period of optimisation. This entails evaluating the performance of individual components of the intervention, and how they interact with one another. One efficient method is the Multiphase Optimisation Strategy (MOST) (Collins, Nahum-Shani \& Almirall, 2014), which involves establishing a set of components that are candidates for inclusion, specifying an optimization criterion for the entire intervention, and then collecting experimental data to identify the subset of components that meet the criterion. Here the term 'component' is broadly defined, and may refer to aspects of the content of the intervention, including any human input; factors affecting engagement, adherence to, fidelity of, or scalability of the intervention including the type of technical platform and presentation features such as gamification; variables and decision rules used to tailor intervention strategy, content, or intensity to individuals; or any other aspect of an intervention that can profitably be separated out for examination (Murray, et al., in press).

The experimental approaches that can be used for optimization include full or fractional factorial experiments (Collins, Dziak \& Li, 2009), the sequential multiple-assignment randomized trial (SMART) (Almirall, Nahum-Shani, Sherwood \& Murphy, 2014), and system identification techniques (Rivera, Pew \& Collins, 2007). The factorial experimental design can be a useful and economical approach for examining the effects of individual intervention components, and is the only experimental design that enables full examination of all interactions.

\section{Towards a taxonomy of DHIs}

It is clear that the content of DHIs, their underpinning theory of change and their mode of delivery will affect the impact of a DHI, yet in most studies these components are not specified or analysed separately. This makes it difficult to judge whether a positive (or 
811 negative) outcome of a trial is the result of: the intervention content and theory of the

812 change, the digital delivery platform or an interaction between the two.

813 Lack of clarity and precision in the terminology used to describe components of DHIs make

814 it difficult to group interventions and identify active components; a situation that is likely

815 to become even more complex as technology develops. An agreed working taxonomy of

816 digital mental health interventions, similar to that developed for behaviour change

817 interventions (the Behaviour Change Technique/BCT Taxonomy Project) (Abraham \&

818 Michie, 2008), is required to enable interventions to be appropriately categorised and

819 analysed. In addition, adherence to the CONSORT eHealth guidelines (Eysenbach \& 820 CONSORT eHealth Group, 2011) would make it easier to take these factors into 821 consideration when comparing individual studies.

822 DHIs that use psychotherapeutic theory as their theoretical basis (e.g. CBT) often do not 823 describe which features of the theory are being employed in the intervention. In a recent 824 review of CBT and behavioural activation (BA) apps for depression (Huguet et al., 2016) 825 produced a checklist of the 'core ingredients' involved in CBT and BA approaches (e.g. 826 challenging negative thoughts in CBT; activity scheduling of pleasant and avoidance 827 behaviours in BA), which enabled them to identify the 'ingredients' available in apps. 828 Similarly, digital interventions with gaming features (often called 'serious games') use 829 specific gaming elements in their delivery, such as having a storyline and setting rules, 830 goals, and objectives (Fleming, et al., 2014). It may be useful to apply a similar BCT 831 Taxonomy approach to DHIs so that clinicians and the public can clearly see how these 832 interventions aim to produce therapeutic change and researchers can judge their 833 effectiveness.

834 Related to this issue is the large number of different digital interventions being studied, all 835 of which differ to a greater or lesser degree according to their purpose, content, theory of 836 change, presentation interface and mode of delivery. As a result, it is difficult for DHIs to 837 undergo the incremental innovation seen in other areas of healthcare. An agreed taxonomy 
for specifying the components of DHIs is required for replication of trial results, comparison between DHI, synthesising data across trials in systematic reviews and meta-analyses.

\section{Tailoring and personalisation of DHIs}

841 In health behaviour change interventions, 'tailoring' typically refers to how targeted the 842 health messages being sent to users are. For example, 'generic' communication reflects messages that are not individualised to the recipient's specific needs, but this may be

844 'personalised' by adding a user characteristic to the message (e.g. the user's name). 845 'Targeted' communication is used to provide messages to a specific group, such as those of a specific age or who screen for a specific risk of developing a health problem (Musiat,

847 Hoffmann \& Schmidt, 2012; Noar, Benac \& Harris, 2007). Our review found similar approaches for mental health DHIs. For example, some received 'personalised' feedback in the form of information based on an assessment or data that was entered into the

850 intervention, which can vary in its degree of personalisation (Barak \& Grohol, 2011; Musiat, et al., 2012). Tailoring may also mean that an intervention has different user 'pathways' depending on, for example, the user's baseline symptoms (e.g. Chiauzzi,

853 Brevard, Thum, Decembrele \& Lord, 2008), or allows users to choose the modules or content that is most relevant to their presenting problem (e.g. Andersson, Estling, Jakobsson, Cuijpers \& Carlbring, 2011).

Research has shown that users want this type of tailoring or personalisation. Adults with experience of using computerised therapies reported a desire for DHIs to be responsive to

858 the 'self' (e.g. sensitive to their clinical needs, feelings and personal preferences) (Knowles 859 et al., 2014). The research team responsible for the SPARX DHI also provides examples of good practice in this area. In focus groups with rural Australian adolescents (Cheek, et al., 2014), 'personalisation' of SPARX was a key theme that emerged. This reflected two

862 separate aspects valued by adolescents. The first centres on their personal choice to use 863 the intervention (e.g. where and when to use it) and who to share their feelings and the intervention with (e.g. with a counsellor or adult). The second centres on the personalisation of the intervention, which focused mainly on the ability of the user to 
866 choose the gender of the 'guide' avatar, which they reported led to improved relatability.

867 This aspect was also highlighted and praised by sexual minority youth, who felt that 868 allowing them to personalise the avatar's gender and appearance reflected their real-world experience of challenging gender expectations (Lucassen et al., 2013). Furthermore, the

870 research team have analysed qualitative data from five studies of SPARX to understand

871 how users' perceptions and elements of the intervention map onto the autonomy, 872 competence and relatedness aspects of self-determination theory, which in turn have been 873 theorised as key factors influencing engagement and adherence to computerised 874 interventions (Cheek et al., 2015).

875 Although the research on tailoring and personalisation for DHIs and the benefits that may 876 result from this is limited at present, it does suggest that the ability of a young person to 877 personalise relatively small features (e.g. the gender and appearance of a 'guide') may 878 have an impact on how users view and relate to a DHI. Further research is required to 879 explore how DHIs should be tailored and how this influences uptake, adherence, 880 satisfaction and outcomes.

\section{Privacy and security issues}

882 Privacy and security are important concerns when handling and managing health-related 883 data (Hollis, et al., 2015), as users may be concerned about where their information goes, 884 how it is stored, and who it is shared with. For example, when installing a new app on a 885 smartphone, the user will be asked for permission to access or read specific phone 886 functions, and some users may be concerned about why an app has to access such 887 information. When using internet-enabled technologies, adolescents and young people 888 have expressed concerns about data protection and security, and the information they 889 chose to share with the technology (Ring, 2014). In seeking user opinions about 890 developing an online mental health clinic, university students stated that data security in 891 online peer-to-peer interactions was paramount, and anonymity may help in maintaining 892 trust and privacy of access (Farrer, Gulliver, Chan, Bennett \& Griffiths, 2015). Users have 893 to make the decision to trust apps based on the information provided to them, and so 
894 transparency is needed to help users understand how ethically their data is managed and 895 stored (Huckvale, Prieto, Tilney, Benghozi \& Car, 2015). Understandably these concerns 896 are also applicable to other non-app DHIs, and research is needed to gather CYPs' opinions, concerns and requirements regarding data security and privacy of DHIs.

\section{Do children and young people prefer digital health interventions?}

899 Bradford and Rickwood (2014) found no evidence to confirm the assumption that young people in Australia prefer digital or internet-delivered help over FtF or phone-based services. While young people expressed some positive attitudes towards DHIs, overall they had a strong preference for FtF help (59\%), with only $16 \%$ expressing a preference for online treatment (lower than the number of CYP who reported that they would not seek help at all). CYP reported that the perceived benefits of FtF help (e.g. more personal, can see who they are talking to, customised feedback) are valued as important when receiving mental health treatment. Furthermore, in a study of young people attending a UK CAMHS clinic (Stallard, Velleman \& Richardson, 2010) found that half were not interested in CCBT, preferring to talk to someone FtF. These somewhat discouraging findings suggest that the common assumption that DHIs are the preferred form of intervention and service contact

910 for CYP may be unfounded, or at least over simplified and would benefit from further 911 exploration using qualitative research methods.

912 Qualitative research to date has shown that CYP have a number of concerns about DHIs 913 that could prevent uptake and adherence. Some of these issues are applicable to mental 914 health services in general and are concerned with stigma, embarrassment and shame 915 (Clement et al., 2015). Other factors are specifically related to accessing digital 916 interventions, and include: reduced motivation to engage in CCBT without reinforcement; 917 inadequate access to information about DHIs and their effectiveness; lack of technological 918 access; the belief that DHIs may be impersonal with limited interaction; lack of tailoring 919 to their specific presenting problems; and acceptability of DHIs for CYP at different ages 920 and developmental stages (Fleming, Dixon, Frampton \& Merry, 2012; Lal et al., 2015; 
921 Lucassen et al., 2015; Mitchell \& Gordon, 2007; Pretorius, et al., 2010; Richards \&

922 Timulak, 2013)

923 Despite identifying their limitations, CYP also report perceived benefits to using DHIs.

924 Research with young people both with and without experience of using DHIs, has identified 925 positive attributes of DHIs including; privacy and anonymity, flexibility, reduced pressure 926 and ability to complete interventions on their own terms, facilitating self-management, 927 and being experienced as less 'intense' than counselling (Bradley, Robinson \& Brannen, 928 2012; Fleming, Lucassen, Stasiak, Shepherd \& Merry, 2015; Mitchell \& Gordon, 2007; 929 Pretorius, et al., 2010; Richards \& Timulak, 2013; Simons, et al., 2016). Young people 930 value information, accessibility, self-reliance and control when accessing mental health services (Plaistow et al., 2014). DHIs are usually considered 'more accessible', and online resources are considered a way of enabling young people to have control, privacy and independence when accessing mental health resources (Cheek, et al., 2014).

While these qualitative findings are encouraging and useful, further qualitative research is required to investigates CYP's perceptions of specific DHIs including the way in which they have been implemented (e.g. within a research framework, services, or 'in the wild'), their perceived mechanisms of change (positive and negative) and recommendations for improved engagement and effectiveness.

\section{How do Healthcare Professionals view the role of DHIs?}

940 The majority of research investigating the views of mental health professionals' (MHPs)

941 has focused on $\mathrm{CCBT}$. There is a consensus among MHPs that FtF therapy is superior to 942 CCBT, despite the evidence (reported in this review and others) that CCBT can be as 943 effective as FtF therapy for depression and anxiety in CYP, at least in the short term and 944 for mild-to-moderate symptoms. The consequence of this is that MHPs tend to believe that 945 DHIs should not be widely and freely available online, and should not be delivered without 946 professional support (Fleming \& Merry, 2013; Stallard, Richardson \& Velleman, 2010; 947 Vigerland, et al., 2016). This view is consistent with the adult cCBT literature (Perle et al., 948 2013) and evidence that MHPs believe DHIs are best offered as an adjunct FtF therapy 
949 (Donovan, Poole, Boyes, Redgate \& March, 2015; Perle, et al., 2013; Simons, et al., 2016;

950 Sinclair, Holloway, Riley \& Auret, 2013; Stallard, Richardson, et al., 2010; Vigerland, et

951 al., 2016). There is also some empirical support for this approach suggesting that a

952

953

954

955

956

957

958

959

960

961

962

963

964

965

966

967

968

969

970

971

972

973

974

975

976 combination of CCBT and FtF CBT may be superior to either delivered alone (Sethi, 2013). Interestingly, this view contrasts with the design of most clinical trials which typically evaluate DHIs in isolation from other services and interventions. MHPs have expressed concerns about DHIs in terms of a lack of therapeutic alliance and professional support, lack of tailoring to individual needs, lack of formulation taking into account CYP's family and school context, and difficulties in assessing progress due to a lack of clinical review (Simons, et al., 2016; Stallard, Richardson, et al., 2010; Vigerland, et al., 2016).

MHPs' perceive the main benefits of DHIs as offering increased availability and access to psychological help 'anytime, anywhere', digital technology being an appealing medium for CYP (particularly those who struggle to talk about their feelings), the benefits accompanying self-help such as increased self-confidence and self-awareness, and reduced stigma (Simons, et al., 2016; Stallard, Richardson, et al., 2010; Vigerland, et al., 2016).

\section{Do DHIs widen access to mental health services for CYP?}

In considering the potential for DHIs to widen access to services, it is also important to consider CYP's attitudes towards DHIs. In receiving mental health services and making decisions about treatment, CYP have stated a need for accessibility, self-reliance and control (Plaistow, et al., 2014), and adolescents have stated that CCBT allowed for more control (Fleming, et al., 2015). DHIs are usually considered more accessible through their virtue of being accessed remotely via technology, at a time and place of the young person's choosing and online resources are considered a medium that allows young people to have control, privacy, and independence (Cheek, et al., 2014).

At present, there is a lack of data on whether DHIs can close the gap between supply and demand for mental health interventions in CYP and crucially, whether they reach populations currently underserved by traditional face to face services. There is a pressing 
977 need to understand more about the individual characteristics of children and young people

978 who benefit most from DHIs as well as those characteristics that suggest DHIs would be

979 unhelpful or contra-indicated. Research is also needed to understand where best DHIs are

980 placed in existing care pathways. For example, should self-guided cCBT for depression be

981 offered routinely before face to face therapy, or alternatively in parallel with face to face

982 therapy to augment adherence and effectiveness? Similarly, should young people be

983 signposted to specific DHIs only after online or FtF assessment? High quality health

984 services research is needed to answer these questions.

\section{SUMMARY}

986 In recent years there has been a rapid growth in the development and evaluation of DHIs 987 for mental health problems in CYP. While the evidence we reviewed provides some support 988 for cCBT as a treatment intervention approach for mild to moderate depression and 989 anxiety, the benefits remain uncertain for other clinical areas. There is also insufficient 990 research investigating the 'active' and critical components of these interventions. We recommend that future research should focus on identifying these 'active ingredients', i.e.

992 the individual components or specific mechanisms of change in CCBT and other DHIs that 993 are most effective for improving uptake, adherence and clinical outcomes in CYP.

994 A notable finding of our meta-review was that the research in this area (190 individual papers) described 147 unique DHIs. Hence, a major challenge for the field is to develop an agreed taxonomy to assist the identification of common active components of different

997 interventions. We would argue that a more efficient and theoretically sound approach would be to develop DHIs through a process of optimisation by incorporating and testing existing evidence-based components which act as 'core' building blocks for new DHIs.

The majority of DHIs have been designed to help CYP at risk for developing, or with a diagnosis of, an anxiety disorder (including generalised anxiety, social anxiety, and specific 1002 phobia) and/or depression. Our review also identified a small number of trials of DHIs for ADHD, ED and ASD. However, areas such as psychosis, PTSD (and other specific anxiety 
1004

1005

1006

1007

1008

1009

1010

1011

1012

1013

1014

1015

1016

1017

1018

1019

1020

1021

1022

1023

1024

1025

1026

1027

1028

1029

1030

1031

disorders) are under-researched, while conditions such as Tourette Syndrome, conduct disorder, substance misuse and emerging personality disorder (or interpersonal problems) have been completely overlooked thus far. DHIs for ADHD have focussed predominantly on 'brain training' approaches using computerised WMT and CF training and EEG NFT. Future research should explore how these approaches transfer onto real-world outcomes, and if benefits are sustained and generalised outside the context of the specific computerised training tasks. Furthermore, there is a need for more non-pharmacological approaches that harness mobile (mHealth) DHIs, including wearable technologies, to treat and manage ADHD (Tarver, Daley, Lockwood \& Sayal, 2014). More research is required on the role of factors such as reminders and human facilitation to understand whether it is possible to identify an 'optimum level' or whether it is preferable and feasible for each individual to design their own.

Human facilitation/support is an important factor in influencing uptake, engagement and outcomes of DHIs. It appears that 'blended' DHIs that include human facilitation/support may achieve greater engagement, treatment adherence and improved retention in intervention trials. However, we are unable to draw any firm conclusions about what form, and how much human support, is most effective for CYP as a whole, let alone more specific user groups. It is important to note that the type and level of human support provided to encourage retention in trials is not necessarily practicable or transferable to routine clinical settings; therefore, it is unlikely that retention rates (and outcomes) reported in trials can be achieved if DHIs are implemented as unguided/unsupported interventions outside trial settings. Our results suggest that the level of support provided within trials for children is more substantial, particularly for ASD and ADHD. Furthermore, the characteristics of DHIs that support engagement at different ages requires further research. It is likely that DHIs for children need to incorporate more interactive, game-like elements so that the development of skills and progression through the intervention becomes self-reinforcing. Findings from the meta-review suggest that for CCBT, greater benefits are found in older CYP. The limited effectiveness of DHIs for mood disorders in younger children may result 
1032 from insufficient adaptation of interventions to children's cognitive and developmental 1033 needs (Adelman et al. 2014).

1034 Research investigating the use and effectiveness of mHealth smartphone/tablet apps was 1035 mostly absent from our review. This area of healthcare delivery is growing for adult 1036 populations (East \& Havard, 2015; Mani, Kavanagh, Hides \& Stoyanov, 2015; Nicholas, 1037 Larsen, Proudfoot \& Christensen, 2015). There are several commercially available 1038 Mindfulness interventions in a mobile application format that could have trans-diagnostic 1039 benefits for mental health (Mani, et al., 2015), but these have not been evaluated with 1040 CYP. Mobile apps may also be conceptualised as add-ons to online interventions, for 1041 example to make material available to users whilst on the go. Apps may also provide a 1042 means of supplementing therapy (both FtF and online) by allowing, for example, remote 1043 monitoring of symptoms (Simons, et al., 2016). Second generation DHIs also incorporate 1044 wearable devices (e.g. activity monitors), which have been more widely explored in the 1045 health psychology and behaviour change field for CYP (Turner, Spruijt-Metz, Wen \& Hingle, 1046 2015). The rise in research on mental health-related apps and the potential behaviour 1047 change arising from wearables suggests a more holistic approach to digital interventions 1048 is on the horizon, with a blurring of boundaries between digital assessment, monitoring 1049 and interventions. However, this will also add to the complexity of assessing efficacy and 1050 determining the active components of an intervention. Virtual reality interventions were 1051 also absent from our review results. In adults, virtual reality interventions for mental 1052 health have predominantly focused on enhancing existing interventions such as exposure 1053 therapy for specific phobias (Pan, Gillies, Barker, Clark \& Slater, 2012) or PTSD (Gerardi, 1054 Cukor, Difede, Rizzo \& Rothbaum, 2010). However, new research is expanding into areas 1055 such as depression (Falconer et al., 2016), psychosis (Leff, Williams, Huckvale, Arbuthnot 1056 \& Leff, 2013) and EDs (Marco, Perpiñá \& Botella, 2013).

\section{CONCLUSIONS}

1058 DHIs offer huge potential for widening access, increasing efficiency and improving 1059 healthcare outcomes. However, existing research indicates that benefits have yet to be 
1060

1061

1062

1063

1064

1065

1066

1067

1068

1069

1070

1071

1072

1073

1074

1075

1076

1077

1078

1079

1080

1081

1082

1083

1084

1085

1086

1087

fully realised and effectiveness of these approaches remains uncertain. For the field to realise the full potential of DHIs, it is necessary to simultaneously harness the latest technological innovations while maintaining a robust evidence base of clinical and costeffectiveness. Meeting this challenge requires a novel integration of innovative approaches and research methods drawn from disparate disciplines and academic traditions. To date, the methods for developing and evaluating DHIs have borrowed largely from approaches used with psychological and pharmacological interventions. However, the development and evaluation of DHIs requires different approaches with integration and inter-disciplinary collaboration between methodologies and approaches drawn from engineering, computer science, human factors, human computer interaction, psychology and mental health services research.

From a clinical perspective, we recommend that an integrated approach should be developed that takes into account the views of CYP, the opinions of MHPs (gatekeepers of DHIs), and seeks to blend DHIs with FtF therapy. MHPs emphasise the importance of DHI's being adjuncts to traditional FtF therapies. Consideration needs to be given to the possible adverse effects of CYP using DHIs outside mental health services on publically available apps. Adverse effects may result from an ineffective or unsuitable intervention, inaccurate health information, leaking of personal information, lack of support, lack of motivation or an exacerbation of symptoms. Consequences of a negative experience of DHIs for CYP such as a lack of faith in efficacy or specific feelings of helplessness, hopelessness and low self-worth may reduce future help seeking behaviour in CYP, which is a particular concern given the recurrent nature of mental health problems (Watsford \& Rickwood, 2014). An additional safeguard for the use of DHIs would be to explicitly highlight the potential negative effects of DHIs. Many interventions do advise users to seek professional help if symptoms deteriorate or do not improve, but we would argue that this does not go far enough.

Future generations of DHIs will also offer seamless integration of real-time passive and active monitoring with personalised therapeutic interventions. In this way, the huge 
potential of digital technology (real-time connectivity of data, ubiquitous reach,

personalisation and convenience) can be best harnessed to improve the effectiveness and

reach of evidence-based psychological therapies for CYP.

1091

1092

1093

1094

1095

1096

1097

1098

1099

1100

1101

1102

1103

1104

1105

1106

1107

1108

1109

1110

1111

1112

1113

1114

1115

1116

1117

1118

1119

1120

1121

1122

1123

1124

1125

1126

1127

1128

1129

1130

1131

1132

1133

1134

1135

1136

1137

1138

1139

\section{References}

Abraham, C., \& Michie, S. (2008). A taxonomy of behavior change techniques used in interventions. Health Psychology, 27(3), 379-387.

Ali, K., Farrer, L., Gulliver, A., \& Griffiths, K. (2015). Online Peer-to-Peer Support for Young People With Mental Health Problems: A Systematic Review JMIR Mental Health, 2(2), e19.

Alkhaldi, G., Hamilton, F. L., Lau, R., Webster, R., Michie, S., \& Murray, E. (2015). The Effectiveness of Technology-Based Strategies to Promote Engagement With Digital Interventions: A Systematic Review Protocol. JMIR Research Protocols, $4(2)$, e47.

Almirall, D., Nahum-Shani, I., Sherwood, N. E., \& Murphy, S. A. (2014). Introduction to SMART designs for the development of adaptive interventions: with application to weight loss research. Translational Behavioral Medicine, 4(3), 260-274.

Andersson, G. (2016). Internet-delivered psychological treatments. Annual Review of Clinical Psychology, 12(12), 12.11-12.23.

Andersson, G., Estling, F., Jakobsson, E., Cuijpers, P., \& Carlbring, P. (2011). Can the Patient Decide Which Modules to Endorse? An Open Trial of Tailored Internet Treatment of Anxiety Disorders. Cognitive Behaviour Therapy, 40(1), 57-64.

Arnold, L. E., Lofthouse, N., Hersch, S., Pan, X., Hurt, E., Bates, B., . . . Grantier, C. (2013). EEG neurofeedback for ADHD: double-blind sham-controlled randomized pilot feasibility trial. Journal of Attention Disorders, 17(5), 410-419. Retrieved from http://onlinelibrary.wiley.com/o/cochrane/clcentral/articles/333/CN00960333/frame.html

Barak, A., \& Grohol, J. M. (2011). Current and Future Trends in Internet-Supported Mental Health Interventions. Journal of Technology in Human Services, 29(3), 155-196.

Barak, A., Klein, B., \& Proudfoot, J. G. (2009). Defining Internet-Supported Therapeutic Interventions. Annals of Behavioral Medicine, 38(1), 4-17.

Beatty, L., \& Binnion, C. (2016). A Systematic Review of Predictors of, and Reasons for, Adherence to Online Psychological Interventions. International Journal of Behavioral Medicine, 1-19.

Bink, M., van Nieuwenhuizen, C., Popma, A., Bongers, I. L., \& van Boxtel, G. J. M. (2015). Behavioral effects of neurofeedback in adolescents with ADHD: a randomized controlled trial. European Child and Adolescent Psychiatry, 24(9), 1035-1048.

Bink, M., Van Nieuwenhuizen, C., Popma, A., Bongers, L. L., \& Van Boxtel, G. J. M. (2014). Neurocognitive effects of neurofeedback in adolescents with ADHD: A randomized controlled trial. Journal of Clinical Psychiatry, 75(5), 535-542.

Boogerd, E. A., Arts, T., Engelen, L. J., \& van de Belt, T. H. (2015). "What Is eHealth": Time for An Update? JMIR Research Protocols, 4(1), e29.

Boydell, K. M., Hodgins, M., Pignatiello, A., Teshima, J., Edwards, H., \& Willis, D. (2014). Using technology to deliver mental health services to children and youth: a scoping review. Journal of the Canadian Academy of Child and Adolescent Psychiatry, 23(2), 87-99.

Bradford, S., \& Rickwood, D. (2014). Adolescent's preferred modes of delivery for mental health services. Child and Adolescent Mental Health, 19(1), 39-45.

Bradley, K. L., Robinson, L. M., \& Brannen, C. L. (2012). Adolescent help-seeking for psychological distress, depression, and anxiety using an Internet program. International Journal of Mental Health Promotion, 14(1), 23-34. 
1140

1141

1142

1143

1144

1145

1146

1147

1148

1149

1150

1151

1152

1153

1154

1155

1156

1157

1158

1159

1160

1161

1162

1163

1164

1165

1166

1167

1168

1169

1170

1171

1172

1173

1174

1175

1176

1177

1178

1179

1180

1181

1182

1183

1184

1185

1186

1187

1188

1189

1190

1191

1192

1193

1194

1195

1196

Calear, A. L., \& Christensen, H. (2010). Review of internet-based prevention and treatment programs for anxiety and depression in children and adolescents. Medical Journal of Australia, 192(11 Suppl), S12-14.

Chacko, A., Bedard, A. C., Marks, D. J., Feirsen, N., Uderman, J. Z., Chimiklis, A., . . . Ramon, M. (2014). A randomized clinical trial of Cogmed Working Memory Training in school-age children with ADHD: a replication in a diverse sample using a control condition. Journal of Child Psychology and Psychiatry, 55(3), 247-255. Retrieved from http://onlinelibrary.wiley.com/o/cochrane/clcentral/articles/913/CN01050913/frame.html

Cheek, C., Bridgman, H., Fleming, T., Cummings, E., Ellis, L., Lucassen, F. G. M., ... Skinner, T. (2014). Views of Young People in Rural Australia on SPARX, a Fantasy World Developed for New Zealand Youth With Depression. JMIR Serious Games, 2(1), e3.

Cheek, C., Fleming, T., Lucassen, M. F. G., Bridgman, H., Stasiak, K., Shepherd, M., \& Orpin, P. (2015). Integrating Health Behavior Theory and Design Elements in Serious Games. JMIR Mental Health, 2(2), e11.

Chiauzzi, E., Brevard, J., Thum, C., Decembrele, S., \& Lord, S. (2008). MyStudentBodyStress: an online stress management intervention for college students. J Health Commun, 13(6), 555-572.

Christensen, H., Griffiths, K. M., \& Korten, A. (2002). Web-based cognitive behavior therapy: analysis of site usage and changes in depression and anxiety scores. $J$ Med Internet Res, 4(1).

Clarke, A. M., Kuosmanen, T., \& Barry, M. M. (2015). A Systematic Review of Online Youth Mental Health Promotion and Prevention Interventions. Journal of Youth and Adolescence, 44(1), 90-113.

Clement, S., Schauman, O., Graham, T., Maggioni, F., Evans-Lacko, S., Bezborodovs, N., . . . Thornicroft, G. (2015). What is the impact of mental health-related stigma on help-seeking? A systematic review of quantitative and qualitative studies. Psychological Medicine, 45(01), 11-27.

Collins, L. M., Dziak, J. J., \& Li, R. (2009). Design of Experiments with Multiple Independent Variables: A Resource Management Perspective on Complete and Reduced Factorial Designs. Psychological methods, 14(3), 202-224.

Collins, L. M., Nahum-Shani, I., \& Almirall, D. (2014). Optimization of behavioral dynamic treatment regimens based on the sequential, multiple assignment, randomized trial (SMART). Clinical trials (London, England), 11(4), 426-434.

Collishaw, S. (2015). Annual Research Review: Secular trends in child and adolescent mental health. Journal of Child Psychology and Psychiatry, 56(3), 370-393.

Cortese, S., Ferrin, M., Brandeis, D., Buitelaar, J., Daley, D., Dittmann, R. W., . . . European ADHD Guidelines Group. (2015). Cognitive Training for AttentionDeficit/Hyperactivity Disorder: Meta-Analysis of Clinical and Neuropsychological Outcomes From Randomized Controlled Trials. Journal of the American Academy of Child and Adolescent Psychiatry, 54(3), 164-174.

Cortese, S., Ferrin, M., Brandeis, D., Holtmann, M., Aggensteiner, P., Daley, D., . . . Zuddas, A. (2016). Neurofeedback for Attention-Deficit/Hyperactivity Disorder: Meta-Analysis of Clinical and Neuropsychological Outcomes From Randomized Controlled Trials. Journal of the American Academy of Child \& Adolescent Psychiatry, 55(6), 444-455.

Davies, E. B., Morriss, R., \& Glazebrook, C. (2014). Computer-Delivered and Web-Based Interventions to Improve Depression, Anxiety, and Psychological Well-Being of University Students: A Systematic Review and Meta-Analysis. Journal of Medical Internet Research, 16(5).

Davies, S. (2014). Annual Report of the Chief Medical Officer 2013, Public Mental Health Priorities: Investing in the Evidence. London, UK: Department of Health.

Dongen-Boomsma, M., Vollebregt, M. A., Buitelaar, J. K., \& Slaats-Willemse, D. (2014). Working memory training in young children with ADHD: A randomized placebocontrolled trial. Journal of Child Psychology and Psychiatry, 55(8), 886-896. 
Dongen-Boomsma, M., Vollebregt, M. A., Slaats-Willemse, D., \& Buitelaar, J. K. (2013). A randomized placebo-controlled trial of electroencephalographic (EEG) neurofeedback in children with attention-deficit/hyperactivity disorder. The Journal of Clinical Psychiatry, 74(8), 821-827. Retrieved from http://onlinelibrary.wiley.com/o/cochrane/clcentral/articles/701/CN00962701/frame.html

Donovan, C. L., Poole, C., Boyes, N., Redgate, J., \& March, S. (2015). Australian mental health worker attitudes towards CCBT: What is the role of knowledge? Are there differences? Can we change them? Internet Interventions, 2(4), 372-381.

Dovis, S., Oord, S., Wiers, R. W., \& Prins, P. J. M. (2015). Improving executive functioning in children with ADHD: Training multiple executive functions within the context of a computer game. A randomized double-blind placebo controlled trial. PloS One, 10(4). Retrieved from http://onlinelibrary.wiley.com/o/cochrane/clcentral/articles/071/CN01071071/frame.html

East, M. L., \& Havard, B. C. (2015). Mental Health Mobile Apps: From Infusion to Diffusion in the Mental Health Social System. JMIR Mental Health, 2(1), e10.

Ebert, D. D., Zarski, A. C., Christensen, H., Stikkelbroek, Y., Cuijpers, P., Berking, M., \& Riper, H. (2015). Internet and Computer-Based Cognitive Behavioral Therapy for Anxiety and Depression in Youth: A Meta-Analysis of Randomized Controlled Outcome Trials. PLoS One, 10(3).

Egeland, J., Aarlien, A. K., \& Saunes, B. K. (2013). Few Effects of Far Transfer of Working Memory Training in ADHD: A Randomized Controlled Trial. PloS One, $8(10)$. Retrieved from http://onlinelibrary.wiley.com/o/cochrane/clcentral/articles/553/CN00913553/frame.html

Eysenbach, G. (2001). What is e-health? Journal of Medical Internet Research, 3(2), e20.

Eysenbach, G., \& CONSORT eHealth Group. (2011). CONSORT-EHEALTH: Improving and Standardizing Evaluation Reports of Web-based and Mobile Health Interventions. Journal of Medical Internet Research, 13(4), e126.

Falconer, C. J., Rovira, A., King, J. A., Gilbert, P., Antley, A., Fearon, P., . . Brewin, C. R. (2016). Embodying self-compassion within virtual reality and its effects on patients with depression. British Journal of Psychiatry Open, 2(1), 74-80.

Farrer, L., Gulliver, A., Chan, J. K., Batterham, P. J., Reynolds, J., Calear, A., . . . Griffiths, K. M. (2013). Technology-based interventions for mental health in tertiary students: systematic review. Journal of Medical Internet Research, 15(5).

Farrer, L., Gulliver, A., Chan, K. Y. J., Bennett, K., \& Griffiths, M. K. (2015). A Virtual Mental Health Clinic for University Students: A Qualitative Study of End-User Service Needs and Priorities. JMIR Mental Health, 2(1), e2.

FDA U.S. Food \& Drug Administration. (2014). Benefit-Risk Factors to Consider When Determining Substantial Equivalence in Premarket Notifications [510(k)] With Different Technological Characteristics Draft Guidance for Industry and Food and Drug Administration Staff. . Rockville, MD, USA.

Fleming, T., Cheek, C., Merry, S., Thabrew, H., Bridgman, H., Stasiak, K., . . Hetrick, S. (2014). Serious games for the treatment or prevention of depression: A systematic review. Revista de Psicopatología y Psicología Clínica, 19(3), 227-242.

Fleming, T., Dixon, R., Frampton, C., \& Merry, S. (2012). A Pragmatic Randomized Controlled Trial of Computerized CBT (SPARX) for Symptoms of Depression among Adolescents Excluded from Mainstream Education. Behavioural and Cognitive Psychotherapy, 40(05), 529-541.

Fleming, T., Lucassen, M., Stasiak, K., Shepherd, M., \& Merry, S. (2015). The impact and utility of computerised therapy for educationally alienated teenagers: The views of adolescents who participated in an alternative education-based trial. Clinical Psychologist, n/a-n/a. 
Fleming, T., \& Merry, S. (2013). Youth Work Service Providers' Attitudes Towards Computerized CBT for Adolescents. Behavioural and Cognitive Psychotherapy, 41(03), 265-279.

Fletcher-Watson, S., Hammond, S. T., O'Hare, A., Pain, H., Petrou, A., \& McConachie, H. (2013). Click-East: evaluating the impact of an iPad app on social communicative abilities in young children with autism. Paper presented at the International meeting for autism research (2-4 May 2013), San Sebastian, Spain.

Fletcher-Watson, S., Petrou, A., Scott-Barrett, J., Dicks, P., Graham, C., O'Hare, A., . . . McConachie, H. (2015). A trial of an $\mathrm{iPad}^{\mathrm{TM}}$ intervention targeting social communication skills in children with autism. Autism, epub ahead of print.

Gerardi, M., Cukor, J., Difede, J., Rizzo, A., \& Rothbaum, B. O. (2010). Virtual Reality Exposure Therapy for Post-Traumatic Stress Disorder and Other Anxiety Disorders. Current Psychiatry Reports, 12(4), 298-305.

Gilbody, S., Littlewood, E., Hewitt, C., Brierley, G., Tharmanathan, P., Araya, R., . . . White, D. (2015). Computerised cognitive behaviour therapy (CCBT) as treatment for depression in primary care (REEACT trial): large scale pragmatic randomised controlled trial. BMJ, 351.

Hailey, D., Roine, R., \& Ohinmaa, A. (2008). The effectiveness of telemental health applications: a review. Canadian Journal of Psychiatry, 53(11), 769-778.

Hollis, C., Morriss, R., Martin, J., Amani, S., Cotton, R., Denis, M., \& Lewis, S. (2015). Technological innovations in mental healthcare: harnessing the digital revolution. The British Journal of Psychiatry, 206(4), 263-265.

Holzer, L., Urben, S., Passini, C. M., Jaugey, L., Herzog, M. H., Halfon, O., \& Pihet, S. (2014). A randomized controlled trial of the effectiveness of computer-assisted cognitive remediation (CACR) in adolescents with psychosis or at high risk of psychosis. Behavioural and Cognitive Psychotherapy, 42(4), 421-434.

Huckvale, K., Prieto, J. T., Tilney, M., Benghozi, P.-J., \& Car, J. (2015). Unaddressed privacy risks in accredited health and wellness apps: a cross-sectional systematic assessment. BMC Medicine, 13(1), 1-13.

Huguet, A., Rao, S., McGrath, P. J., Wozney, L., Wheaton, M., Conrod, J., \& Rozario, S. (2016). A Systematic Review of Cognitive Behavioral Therapy and Behavioral Activation Apps for Depression. PLOS ONE, 11(5), e0154248.

IMS Institute for Healthcare Informatics. (2015). Patient Adoption of mHealth: Use, Evidence and Remaining Barriers to Mainstream Acceptance. Parsippany, NJ.

Jang, J., Dixon, D. R., Tarbox, J., Granpeesheh, D., Kornack, J., \& de Nocker, Y. (2012). Randomized trial of an eLearning program for training family members of children with autism in the principles and procedures of applied behavior analysis. Research in Autism Spectrum Disorders, 6(2), 852-856.

Johansson, R., \& Andersson, G. (2012). Internet-based psychological treatments for depression. Expert Review of Neurotherapeutics, 12(7), 861-870.

Johnson, K. R., Fuchs, E., Horvath, K. J., \& Scal, P. (2015). Distressed and Looking for Help: Internet Intervention Support for Arthritis Self-Management. Journal of Adolescent Health, 56(6), 666-671.

Joyce, S., Modini, M., Christensen, H., Mykletun, A., Bryant, R., Mitchell, P. B., \& Harvey, S. B. (2015). Workplace interventions for common mental disorders: a systematic meta-review. Psychological Medicine, 46(4), 683-697.

Källander, K., Tibenderana, J. K., Akpogheneta, O. J., Strachan, D. L., Hill, Z., ten Asbroek, A. H. A., . . Meek, S. R. (2013). Mobile Health (mHealth) Approaches and Lessons for Increased Performance and Retention of Community Health Workers in Low- and Middle-Income Countries: A Review. Journal of Medical Internet Research, 15(1), e17.

Kass, A. E., Trockel, M., Safer, D. L., Sinton, M. M., Cunning, D., Rizk, M. T., . . . Taylor, C. B. (2014). Internet-based preventive intervention for reducing eating disorder risk: A randomized controlled trial comparing guided with unguided self-help. Behaviour Research and Therapy, 63, 90-98. Retrieved from http://onlinelibrary. wiley.com/o/cochrane/clcentral/articles/316/CN01022316/frame.html 
Kauer, S. D., Reid, S. C., Sanci, L., \& Patton, G. C. (2009). Investigating the utility of mobile phones for collecting data about adolescent alcohol use and related mood, stress and coping behaviours: Lessons and recommendations. Drug and Alcohol Review, 28(1), 25-30.

Knowles, S. E., Toms, G., Sanders, C., Bee, P., Lovell, K., Rennick-Egglestone, S., . . Bower, P. (2014). Qualitative Meta-Synthesis of User Experience of Computerised Therapy for Depression and Anxiety. PLoS ONE, 9(1), e84323.

Kramer, J., Conijn, B., Oijevaar, P., \& Riper, H. (2014). Effectiveness of a web-based solution-focused brief chat treatment for depressed adolescents and young adults: Randomized controlled trial. Journal of Medical Internet Research, 16(5), 40-50. Retrieved from http://onlinelibrary.wiley.com/o/cochrane/clcentral/articles/195/CN01039195/frame.html

Lal, S., Dell'Elce, J., Tucci, N., Fuhrer, R., Tamblyn, R., \& Malla, A. (2015). Preferences of Young Adults With First-Episode Psychosis for Receiving Specialized Mental Health Services Using Technology: A Survey Study. JMIR Mental Health, 2(2), e18.

Leff, J., Williams, G., Huckvale, M. A., Arbuthnot, M., \& Leff, A. P. (2013). Computerassisted therapy for medication-resistant auditory hallucinations: proof-ofconcept study. The British Journal of Psychiatry.

Li, L., Yang, L., Zhuo, C. J., \& Wang, Y. F. (2013). A randomised controlled trial of combined EEG feedback and methylphenidate therapy for the treatment of ADHD. Swiss Medical Weekly, 143. Retrieved from http://onlinelibrary.wiley.com/o/cochrane/clcentral/articles/561/CN00916561/frame.html

Lillevoll, K. R., Vangberg, H. C. B., Griffiths, K. M., Waterloo, K., \& Eisemann, M. R. (2014). Uptake and adherence of a self-directed internet-based mental health intervention with tailored e-mail reminders in senior high schools in Norway. BMC Psychiatry, 14(1). Retrieved from http://onlinelibrary.wiley.com/o/cochrane/clcentral/articles/113/CN00979113/frame.html

Lucassen, M. F., Hatcher, S., Fleming, T. M., Stasiak, K., Shepherd, M. J., \& Merry, S. N. (2015). A qualitative study of sexual minority young people's experiences of computerised therapy for depression. Australasian Psychiatry, 23(3), 268-273.

Lucassen, M. F. G., Hatcher, S., Stasiak, K., Fleming, T., Shepherd, M., \& Merry, S. N. (2013). The views of lesbian, gay and bisexual youth regarding computerised self-help for depression: An exploratory study. Advances in Mental Health, 12(1), 22-33.

Mani, M., Kavanagh, D. J., Hides, L., \& Stoyanov, S. R. (2015). Review and Evaluation of Mindfulness-Based iPhone Apps. JMIR mHealth and uHealth, 3(3), e82.

Marco, J. H., Perpiñá, C., \& Botella, C. (2013). Effectiveness of cognitive behavioral therapy supported by virtual reality in the treatment of body image in eating disorders: One year follow-up. Psychiatry Research, 209(3), 619-625.

Melby-Lervåg, M., \& Hulme, C. (2012). Is Working Memory Training Effective? A MetaAnalytic Review. Developmental Psychology, 49(2), 270-291.

Melnyk, B. M., Amaya, M., Szalacha, L. A., Hoying, J., Taylor, T., \& Bowersox, K. (2015). Feasibility, acceptability, and preliminary effects of the COPE online cognitivebehavioral skill-building program on mental health outcomes and academic performance in freshmen college students: A randomized controlled pilot study. Journal of Child and Adolescent Psychiatric Nursing, 28(3), 147-154.

Mitchell, N., \& Gordon, P. K. (2007). Attitudes Towards Computerized CBT for Depression Amongst a Student Population. Behavioural and Cognitive Psychotherapy, 35(04), 421-430.

Murray, E., Hekler, E., Andersson, G., Collins, L., Doherty, A., Hollis, C., . . Wyatt, J. (in press). Evaluating Digital Health Interventions: Key questions and approaches. American Journal of Preventive Medicine. 
Musiat, P., Hoffmann, L., \& Schmidt, U. (2012). Personalised computerised feedback in E-mental health. Journal of Mental Health, 21(4), 346-354.

Myers, K., Vander Stoep, A., Zhou, C., McCarty, C. A., \& Katon, W. (2015). Effectiveness of a telehealth service delivery model for treating attention-deficit/hyperactivity disorder: A community-based randomized controlled trial. Journal of the American Academy of Child and Adolescent Psychiatry, 54(4), 263-274. Retrieved from http://onlinelibrary.wiley.com/o/cochrane/clcentral/articles/950/CN$\underline{01068950 / \text { frame.html }}$

http://ac.els-cdn.com/S0890856715000398/1-s2.0-S0890856715000398main.pdf? tid $=a 3 e 2 c 7 e 0-b b 7 e-11 e 5-a 8 b 3-$ 00000aacb361\&acdnat $=1452859009$ b91fc1be333b6f8dde66a9e77d2ca710

Naslund, J. A., Marsch, L. A., McHugo, G. J., \& Bartels, S. J. (2015). Emerging mHealth and eHealth interventions for serious mental illness: a review of the literature. Journal of Mental Health, 24(5), 321-332.

NCCMH. (2014). E-therapies systematic review for children and young people with mental health problems. London, UK.

Newton, M. S., \& Ciliska, D. (2006). Internet-based innovations for the prevention of eating disorders: a systematic review. Eating Disorders: The Journal of Treatment \& Prevention, 14(5), 365-384.

Nicholas, J., Larsen, M. E., Proudfoot, J., \& Christensen, H. (2015). Mobile Apps for Bipolar Disorder: A Systematic Review of Features and Content Quality. Journal of Medical Internet Research, 17(8), e198.

Noar, S. M., Benac, C. N., \& Harris, M. S. (2007). Does tailoring matter? Meta-analytic review of tailored print health behavior change interventions. Psychological Bulletin, 133(4), 673-693.

Palmqvist, B., Carlbring, P., \& Andersson, G. (2007). Internet-delivered treatments with or without therapist input: does the therapist factor have implications for efficacy and cost? Expert Review of Pharmacoeconomics \& Outcomes Research, 7(3), 291-297.

Pan, X., Gillies, M., Barker, C., Clark, D. M., \& Slater, M. (2012). Socially Anxious and Confident Men Interact with a Forward Virtual Woman: An Experimental Study. PLOS ONE, 7(4), e32931.

Pennant, M. E., Loucas, C. E., Whittington, C., Creswell, C., Fonagy, P., Fuggle, P., . . . Expert Advisory, G. (2015). Computerised therapies for anxiety and depression in children and young people: A systematic review and meta-analysis. Behaviour Research and Therapy, 67, 1-18.

Perle, J. G., Langsam, L. C., Randel, A., Lutchman, S., Levine, A. B., Odland, A. P., . . . Marker, C. D. (2013). Attitudes Toward Psychological Telehealth: Current and Future Clinical Psychologists' Opinions of Internet-Based Interventions. Journal of Clinical Psychology, 69(1), 100-113.

Plaistow, J., Masson, K., Koch, D., Wilson, J., Stark, R. M., Jones, P. B., \& Lennox, B. R. (2014). Young people's views of UK mental health services. Early Intervention in Psychiatry, 8(1), 12-23.

Podina, I., Mogoase, C., David, D., Szentagotai, A., \& Dobrean, A. (2015). A MetaAnalysis on the Efficacy of Technology Mediated CBT for Anxious Children and Adolescents. Journal of Rational-Emotive \& Cognitive-Behavior Therapy, 1-20.

Polanczyk, G. V., Salum, G. A., Sugaya, L. S., Caye, A., \& Rohde, L. A. (2015). Annual Research Review: A meta-analysis of the worldwide prevalence of mental disorders in children and adolescents. Journal of Child Psychology and Psychiatry, 56(3), 345-365.

Pretorius, N., Rowlands, L., Ringwood, S., \& Schmidt, U. (2010). Young people's perceptions of and reasons for accessing a web-based cognitive behavioural intervention for bulimia nervosa. European Eating Disorders Review, 18(3), 197206.

Reyes-Portillo, J. A., Mufson, L., Greenhill, L. L., Gould, M. S., Fisher, P. W., Tarlow, N., \& Rynn, M. A. (2014). Web-Based Interventions for Youth Internalizing Problems: 
1421

1422

1423

1424

1425

1426

1427

1428

1429

1430

1431

1432

1433

1434

1435

1436

1437

1438

1439

1440

1441

1442

1443

1444

1445

1446

1447

1448

1449

1450

1451

1452

1453

1454

1455

1456

1457

1458

1459

1460

1461

1462

1463

1464

1465

1466

1467

1468

1469

1470

1471

1472

1473

1474

1475

1476
A Systematic Review. Journal of the American Academy of Child \& Adolescent Psychiatry, 53(12), 1254-1270.e1255.

Rice, S. M., Goodall, J., Hetrick, S. E., Parker, A. G., Gilbertson, T., Amminger, G. P., . . . Alvarez-Jimenez, M. (2014). Online and social networking interventions for the treatment of depression in young people: a systematic review. Journal of Medical Internet Research, 16(9).

Richards, D., \& Timulak, L. (2013). Satisfaction with therapist-delivered vs. selfadministered online cognitive behavioural treatments for depression symptoms in college students. British Journal of Guidance \& Counselling, 41(2), 193-207.

Richardson, T., Stallard, P., \& Velleman, S. (2010). Computerised Cognitive Behavioural Therapy for the Prevention and Treatment of Depression and Anxiety in Children and Adolescents: A Systematic Review. Clinical Child and Family Psychology Review, 13(3), 275-290.

Rickwood, D., \& Bradford, S. (2012). The role of self-help in the treatment of mild anxiety disorders in young people: an evidence-based review. Psychology Research and Behavior Management, 5, 25-36.

Ring, T. (2014). Young people do care about cyber security, SC Magazine. Retrieved from http://www.scmagazineuk.com/young-people-do-care-about-cybersecurity/article/344193/

Rivera, D. E., Pew, M. D., \& Collins, L. M. (2007). Using Engineering Control Principles to Inform the Design of Adaptive Interventions: A Conceptual Introduction. Drug and alcohol dependence, 88(Suppl 2), S31-S40.

Rooksby, M., Elouafkaoui, P., Humphris, G., Clarkson, J., \& Freeman, R. (2015). Internet-assisted delivery of cognitive behavioural therapy (CBT) for childhood anxiety: Systematic review and meta-analysis. Journal of Anxiety Disorders, 29, 83-92.

Ruggiero, K. J., Price, M., Adams, Z., Stauffacher, K., McCauley, J., Danielson, C. K., . . . Resnick, H. S. (2015). Web Intervention for Adolescents Affected by Disaster: Population-Based Randomized Controlled Trial. Journal of the American Academy of Child and Adolescent Psychiatry, 54(9 // R01 MH081056 (NIMH) *National Institute of Mental Health*), 709-717. Retrieved from http://onlinelibrary.wiley.com/o/cochrane/clcentral/articles/288/CN01090288/frame.html

Saekow, J., Jones, M., Gibbs, E., Jacobi, C., Fitzsimmons-Craft, E. E., Wilfley, D., \& Barr Taylor, C. (2015). StudentBodies-eating disorders: A randomized controlled trial of a coached online intervention for subclinical eating disorders. Internet Interventions, 2(4), 419-428. Retrieved from http://onlinelibrary.wiley.com/o/cochrane/clcentral/articles/736/CN01104736/frame.html

Saulsberry, A., Marko-Holguin, M., Blomeke, K., Hinkle, C., Fogel, J., Gladstone, T., . . . Van Voorhees, B. W. (2013). Randomized clinical trial of a primary care internetbased intervention to prevent adolescent depression: One-year outcomes. Journal of the Canadian Academy of Child and Adolescent Psychiatry, 22(2), 106-117.

Schlegl, S., Burger, C., Schmidt, L., Herbst, N., \& Voderholzer, U. (2015). The potential of technology-based psychological interventions for anorexia and bulimia nervosa: a systematic review and recommendations for future research. Journal of Medical Internet Research, 17(3).

Schueller, S. M., Muñoz, R. F., \& Mohr, D. C. (2013). Realizing the Potential of Behavioral Intervention Technologies. Current Directions in Psychological Science, 22(6), 478-483.

Seko, Y., Kidd, S., Wiljer, D., \& McKenzie, K. (2014). Youth mental health interventions via mobile phones: a scoping review. Cyberpsychology, Behavior, and Social Networking, 17(9), 591-602.

Sethi, S. (2013). Treating youth depression and anxiety: A randomised controlled trial examining the efficacy of computerised versus face-to-face cognitive behaviour therapy. Australian Psychologist, 48(4), 249-257. Retrieved from 
http://onlinelibrary.wiley.com/o/cochrane/clcentral/articles/553/CN01038553/frame.html

Shea, B. J., Grimshaw, J. M., Wells, G. A., Boers, M., Andersson, N., Hamel, C., ... Bouter, L. M. (2007). Development of AMSTAR: a measurement tool to assess the methodological quality of systematic reviews. BMC Medical Research Methodology, 7(1), 1-7.

Shechner, T., Rimon-Chakir, A., Britton, J. C., Lotan, D., Apter, A., Bliese, P. D., . . . Bar-Haim, Y. (2014). Attention bias modification treatment augmenting effects on cognitive behavioral therapy in children with anxiety: randomized controlled trial. Journal of the American Academy of Child and Adolescent Psychiatry, 53(1), 6171. Retrieved from http://onlinelibrary.wiley.com/o/cochrane/clcentral/articles/733/CN00961733/frame.html

Siemer, C. P., Fogel, J., \& Van Voorhees, B. W. (2011). Telemental health and webbased applications in children and adolescents. Child \& Adolescent Psychiatric Clinics of North America, 20(1), 135-153.

Simons, L., Valentine, A. Z., Falconer, C., Groom, M., Daley, D., Craven, M. P., . . . Hollis, C. (2016). Developing mHealth remote monitoring technology for Attention Deficit Hyperactivity Disorder: A qualitative study eliciting user priorities and needs. JMIR mHealth and uHealth.

Sinclair, C., Holloway, K., Riley, G., \& Auret, K. (2013). Online Mental Health Resources in Rural Australia: Clinician Perceptions of Acceptability. J Med Internet Res, 15(9), e193.

Smith, P., Scott, R., Eshkevari, E., Jatta, F., Leigh, E., Harris, V., . . Yule, W. (2015). Computerised CBT for depressed adolescents: Randomised controlled trial. Behaviour Research and Therapy, 73, 104-110. Retrieved from http://onlinelibrary.wiley.com/o/cochrane/clcentral/articles/136/CN01090136/frame.html

Sportel, B. E., Hullu, E., Jong, P. J., \& Nauta, M. H. (2013). Cognitive bias modification versus CBT in reducing adolescent social anxiety: a randomized controlled trial. PloS One, 8(5), e64355. Retrieved from http://onlinelibrary.wiley.com/o/cochrane/clcentral/articles/756/CN00963756/frame.html

Stallard, P., Richardson, T., \& Velleman, S. (2010). Clinicians' Attitudes Towards the Use of Computerized Cognitive Behaviour Therapy (CCBT) with Children and Adolescents. Behavioural and Cognitive Psychotherapy, 38(05), 545-560.

Stallard, P., Velleman, S., \& Richardson, T. (2010). Computer Use and Attitudes Towards Computerised Therapy Amongst Young People and Parents Attending Child and Adolescent Mental Health Services. Child and Adolescent Mental Health, 15(2), 80-84.

Stangier, U. (2016). New Developments in Cognitive-Behavioral Therapy for Social Anxiety Disorder. Current Psychiatry Reports, 18(3), 1-8.

Stasiak, K., Hatcher, S., Frampton, C., \& Merry Sally, N. (2014). A pilot double blind randomized placebo controlled trial of a prototype computer-based cognitive behavioural therapy program for adolescents with symptoms of depression. Behavioural and Cognitive Psychotherapy, 42(4), 385-401. Retrieved from http://onlinelibrary.wiley.com/o/cochrane/clcentral/articles/944/CN01038944/frame.html

Steiner, N. J., Frenette, E. C., Rene, K. M., Brennan, R. T., \& Perrin, E. C. (2014). Inschool neurofeedback training for ADHD: Sustained improvements from a randomized control trial. Pediatrics, 133(3), 483-492. Retrieved from http://onlinelibrary. wiley.com/o/cochrane/clcentral/articles/320/CN00981320/frame.html

Storch, E. A., Salloum, A., King, M. A., Crawford, E. A., Andel, R., McBride, N. M., \& Lewin, A. B. (2015). A randomized controlled trial in community mental health centers of computer-assisted cognitive behavioral therapy versus treatment as usual for children with anxiety. Depression and Anxiety, 32(11), 843-852. 
Retrieved from

http://onlinelibrary.wiley.com/o/cochrane/clcentral/articles/385/CN01105385/frame.html

Tarver, J., Daley, D., Lockwood, J., \& Sayal, K. (2014). Are self-directed parenting interventions sufficient for externalising behaviour problems in childhood? A systematic review and meta-analysis. European Child \& Adolescent Psychiatry, 23(12), 1123-1137.

Thomeer, M. L., Smith, R. A., Lopata, C., Volker, M. A., Lipinski, A. M., Rodgers, J. D., . . . Lee, G. K. (2015). Randomized Controlled Trial of Mind Reading and In Vivo Rehearsal for High-Functioning Children with ASD. Journal of Autism and Developmental Disorders, 45(7), 2115-2127. Retrieved from http://onlinelibrary.wiley.com/o/cochrane/clcentral/articles/626/CN01083626/frame.html

Turner, T., Spruijt-Metz, D., Wen, C. K. F., \& Hingle, M. D. (2015). Prevention and treatment of pediatric obesity using mobile and wireless technologies: a systematic review. Pediatric Obesity, 10(6), 403-409.

Urben, S., Pihet, S., Jaugey, L., Halfon, O., \& Holzer, L. (2012). Computer-assisted cognitive remediation in adolescents with psychosis or at risk for psychosis: a 6month follow-up. Acta Neuropsychiatrica, 24(6), 328-335.

Valstar, M., Schuller, B., Smith, K., Almaev, T., Eyben, F., Krajewski, J., . . Pantic, M. (2014). AVEC 2014: 3D Dimensional Affect and Depression Recognition Challenge. Paper presented at the Proceedings of the 4th International Workshop on Audio/Visual Emotion Challenge, Orlando, Florida, USA.

Vigerland, S., Ljotsson, B., Thulin, U., Ost, L. G., Andersson, G., \& Serlachius, E. (2016). Internet-delivered cognitive behavioural therapy for children with anxiety disorders: A randomised controlled trial. Behaviour Research and Therapy, 76, 47-56.

Vries, M., Prins, P. J., Schmand, B. A., \& Geurts, H. M. (2015). Working memory and cognitive flexibility-training for children with an autism spectrum disorder: A randomized controlled trial. Journal of Child Psychology and Psychiatry, 56(5), 566-576.

Watsford, C., \& Rickwood, D. (2014). Young people's expectations, preferences, and experiences of therapy: Effects on clinical outcome, service use, and help-seeking intentions. Clinical Psychologist, 18(1), 43-51.

Wong, N., Kady, L., Mewton, L., Sunderland, M., \& Andrews, G. (2014). Preventing anxiety and depression in adolescents: A randomised controlled trial of two school based Internet-delivered cognitive behavioural therapy programmes. Internet Interventions, 1(2), 90-94. Retrieved from http://onlinelibrary.wiley.com/o/cochrane/clcentral/articles/548/CN00999548/frame.html

World Health Organisation. (2011). mHealth: New horizons for health through mobile technologies Global Observatory for eHealth series - Volume 3. Geneva: World Health Organisation.

Yang, W., Ding, Z., Dai, T., Peng, F., \& Zhang John, X. (2014). Attention bias modification training in individuals with depressive symptoms: A randomized controlled trial. Journal of Behavior Therapy and Experimental Psychiatry, NoSpecified. Retrieved from http://onlinelibrary.wiley.com/o/cochrane/clcentral/articles/191/CN01039191/frame.html

Ye, X. B., Bapuji, S. B., Winters, S. E., Struthers, A., Raynard, M., Metge, C., . . Sutherland, K. (2014). Effectiveness of internet-based interventions for children, youth, and young adults with anxiety and/or depression: a systematic review and meta-analysis. BMC Health Services Research, 14.

Zulman, D. M., Jenchura, E. C., Cohen, D. M., Lewis, E. T., Houston, T. K., \& Asch, S. M. (2015). How Can eHealth Technology Address Challenges Related to Multimorbidity? Perspectives from Patients with Multiple Chronic Conditions. Journal of General Internal Medicine, 30(8), 1063-1070. 
1591 Table 1. Glossary of common terms and abbreviations used in the field of digital 1592 healthcare (Alkhaldi et al., 2015; Andersson, 2016; Barak, Klein \& Proudfoot, 2009; 1593 Källander et al., 2013; Podina, et al., 2015; World Health Organisation, 2011)

\begin{tabular}{|c|c|}
\hline Term & Definition \\
\hline $\begin{array}{l}\text { Digital health } \\
\text { intervention (DHI) }\end{array}$ & $\begin{array}{l}\text { Interventions that provide information, support and therapy } \\
\text { (emotional, decisional, behavioural, and neurocognitive) for } \\
\text { physical and/or mental health problems via a technological or } \\
\text { digital platform (e.g. website, computer, mobile phone } \\
\text { application (app), SMS, email, video-conferencing, wearable } \\
\text { device). }\end{array}$ \\
\hline eHealth & $\begin{array}{l}\text { Electronic Health: Internet-based healthcare delivery, or } \\
\text { anything health-related that uses information and } \\
\text { communications technology (ICT), incorporating computers or } \\
\text { internet in its delivery. }\end{array}$ \\
\hline $\begin{array}{l}\text { Internet, online or } \\
\text { web-based } \\
\text { interventions }\end{array}$ & $\begin{array}{l}\text { Usually refers to a program or service delivered through the } \\
\text { internet (e.g. a website), designed to create a positive change } \\
\text { in behaviour or health status with varying levels of support } \\
\text { (e.g. completely unguided, human-supported) given to user. }\end{array}$ \\
\hline $\begin{array}{l}\text { Computer-based or } \\
\text { computer-delivered } \\
\text { interventions }\end{array}$ & $\begin{array}{l}\text { Similar to internet-based interventions, but usually refers to a } \\
\text { program delivered via a computer: the intervention may be } \\
\text { via the internet or an offline program (e.g. CD-ROM, or } \\
\text { installed software). Includes psychoeducation and } \\
\text { psychotherapy packages, 'serious' games and neurocognitive } \\
\text { 'brain training' interventions. }\end{array}$ \\
\hline
\end{tabular}




\begin{tabular}{|c|c|}
\hline $\begin{array}{l}\text { Computer, internet- } \\
\text { based, or mobile based }\end{array}$ & $\begin{array}{l}\text { The delivery of Cognitive Behavioural Therapy (CBT) via } \\
\text { computer ( } \mathrm{CCBT} \text { ), internet (iCBT) or mobile devices or } \\
\text { applications ( } \mathrm{mCBT} \text { ). Collectively may be referred to as } \\
\text { electronically-delivered CBT (eCBT). }\end{array}$ \\
\hline mHealth & $\begin{array}{l}\text { Mobile-delivered Health: A branch of eHealth focusing on } \\
\text { delivering healthcare-related information, interventions and } \\
\text { monitoring through portable electronic/mobile devices and } \\
\text { technologies, such as smartphones, tablets, and wearable } \\
\text { devices. Examples of mHealth for mental health include } \\
\text { smartphone applications ('apps'), text/SMS-delivered } \\
\text { interventions, and patient monitoring devices. }\end{array}$ \\
\hline $\begin{array}{l}\text { Telehealth, } \\
\text { telepsychiatry, and } \\
\text { telemedicine }\end{array}$ & $\begin{array}{l}\text { Delivery of health services and treatment via } \\
\text { telecommunications technology (e.g. video-conferencing, } \\
\text { SMS email). Includes online counselling and online therapy } \\
\text { that may be synchronous (e.g. real-time video-conferencing) } \\
\text { or asynchronous (e.g. email or SMS). }\end{array}$ \\
\hline
\end{tabular}


Table 2. Summary of the 21 reviews included in the meta-review.

\begin{tabular}{|c|c|c|c|c|c|c|c|}
\hline $\begin{array}{c}\text { Review } \\
\text { authors / } \\
\text { year }\end{array}$ & $\begin{array}{l}\text { Type of } \\
\text { review }\end{array}$ & $\begin{array}{l}\text { Design of studies } \\
\text { in review }\end{array}$ & $\begin{array}{l}\text { Mental health } \\
\text { condition(s) }\end{array}$ & Population and age groups & Digital health interventions & $\begin{array}{l}\text { No. of studies in } \\
\text { review (date } \\
\text { range of search) }\end{array}$ & $\begin{array}{l}\text { AMSTAR } \\
\text { score } \\
\text { (rating)* }\end{array}$ \\
\hline $\begin{array}{l}\text { Ali et al. } \\
\text { (2015) }\end{array}$ & $\begin{array}{l}\text { Systematic } \\
\text { review }\end{array}$ & $\begin{array}{l}\text { RCTs; RTs; Pre-Post } \\
\text { comparisons }\end{array}$ & $\begin{array}{l}\text { Any mental health } \\
\text { condition }\end{array}$ & $\begin{array}{l}\text { Whole review was CAYP: mean } \\
\text { age of sample between 12-25 } \\
\text { years }\end{array}$ & $\begin{array}{l}\text { Online text-based peer-to-peer support } \\
\text { networks and communication (e.g. forums, } \\
\text { online support groups, virtual reality chat) }\end{array}$ & 6 (up to June 2014) & 7 \\
\hline
\end{tabular}

Adolescents: $12-17$ years

Young adults: $18-25$ years

Whole review was CAYP: from 0 -

Whole review was CAYP: from 5- Internet-delivered interventions

19 years and interventions.
Boydell et Scoping

al. (2014) review

No restrictions on

study design

Any mental health

condition

24 years
Technology-based interventions: including video-conferencing, internet-based interventions, email, telephone, mobile apps

$\begin{array}{lllll}\text { Calear } \& & \text { Systematic } & \text { No restrictions on } & \text { Anxiety } & \text { Whole review was CAYP: } \\ \text { Christense } & \text { review } & \text { study design } & \text { Depression } & 19 \text { years } \\ \mathrm{n}(2010) & & & \\ & & & \text { Children: } 5-12 \text { years }\end{array}$

Adolescents: 13-19 years

126 (up to

December 31 2012)

8 (up to June 2009)

4 
Clarke et Systematic

al. (2015) review
RCTs; Experimental

or quasi-

experimental

designs; Pre-Post

comparisons

$\begin{array}{ll}\text { Davies et } & \text { Systematic } \\ \text { al. (2014) } & \text { review and } \\ & \text { meta- } \\ & \text { analysis }\end{array}$

\section{Ebert et al. Meta-}

analysis

RCTs (with non-

active control

condition only)

Anxiety
Depression
Stress
Psychological
distress

\section{Anxiety}

Depression

Whole review was CAYP: up to 25

years old

Computer-based, internet-delivered, or mobile-based CBT interventions

\section{Children: $<13$ years old}

Adolescents: $>13$ years old

\section{Farrer et Systematic RCTs; RTs}

al. (2013) review

Fleming et Systematic

No restrictions on

al. (2014)

review
Any mental health

condition

Depression
University students only: aged

between 18-25 years, or mean

age of sample within this age

range

Review was with all populations,

but all included studies were with

CAYP
Technology-based intervention: accessed

via device (e.g. computer, smartphone) or process (e.g. email, internet)

interventions which utilised elements of

gaming ("serious games")
Online, digital, or computerised
13 (up to December

4 2013)
28 (up to May 


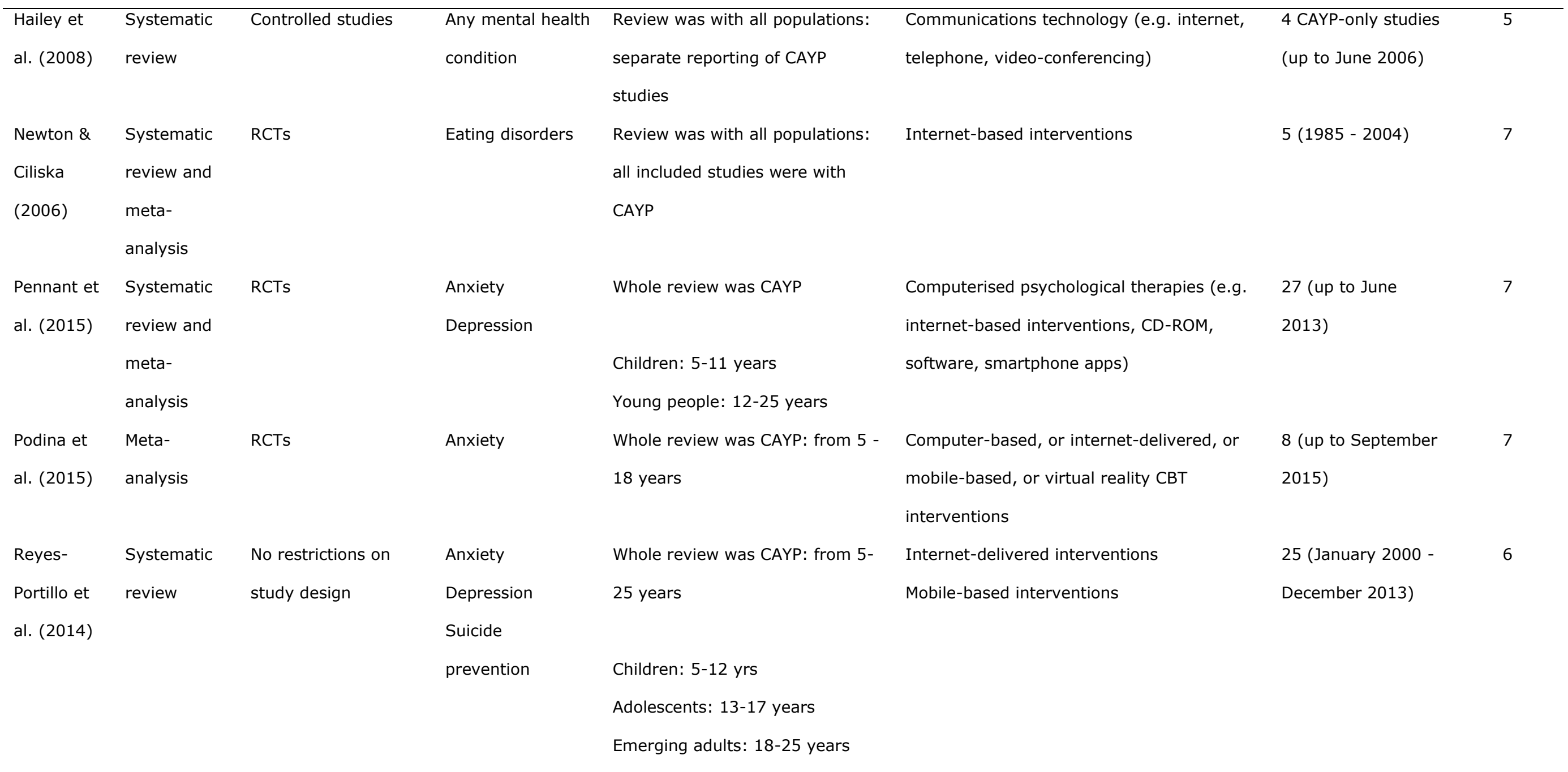




\begin{tabular}{|c|c|c|c|c|c|c|c|}
\hline \multirow{8}{*}{$\begin{array}{l}\text { Rice et al. } \\
\text { (2014) }\end{array}$} & \multirow{8}{*}{$\begin{array}{l}\text { Systematic } \\
\text { review }\end{array}$} & This review had two & \multirow[t]{8}{*}{ Depression } & Whole review was CAYP: from 12- & This review had two sections: & 1) 15 (up to June & \multirow[t]{8}{*}{4} \\
\hline & & sections: & & 25 years & 1) internet-delivered preventative & 2013) & \\
\hline & & 1) RCTs & & & interventions & 2) 22 (up to June & \\
\hline & & 2) any design & & & \multirow{5}{*}{$\begin{array}{l}\text { 2) internet-delivered interventions with } \\
\text { social networking functions }\end{array}$} & \multirow[t]{5}{*}{ 2013) } & \\
\hline & & describing & & & & & \\
\hline & & associations between & & & & & \\
\hline & & social networking use & & & & & \\
\hline & & and depression & & & & & \\
\hline Richardson & Systematic & No restrictions on & Anxiety & Whole review was CAYP: $7-25$ & Computerised CBT (cCBT) or internet- & 10 (from 1980- & 5 \\
\hline $\begin{array}{l}\text { et al. } \\
\text { (2010) }\end{array}$ & review & study design & Depression & years & delivered CBT (iCBT) interventions & 2008) & \\
\hline \multirow{6}{*}{$\begin{array}{l}\text { Rickwood } \\
\text { \& Bradford } \\
\text { (2012) }\end{array}$} & \multirow{6}{*}{$\begin{array}{l}\text { Systematic } \\
\text { review }\end{array}$} & RCTs; Quasi- & \multirow[t]{6}{*}{ Anxiety } & \multirow{6}{*}{$\begin{array}{l}\text { Whole review was CAYP: } 6-25 \\
\text { years }\end{array}$} & Review was of 'self-help interventions: & 5 digital & \multirow[t]{6}{*}{5} \\
\hline & & experimental & & & majority of studies (5 out of 6 ) were & intervention studies & \\
\hline & & designs; Pre-Post & & & computer-based or internet-delivered & (1970 to October & \\
\hline & & comparisons; Case & & & interventions & 2011) & \\
\hline & & studies; Longitudinal & & & & & \\
\hline & & designs & & & & & \\
\hline \multirow{4}{*}{$\begin{array}{l}\text { Rooksby et } \\
\text { al. (2015) }\end{array}$} & Systematic & No restrictions on & \multirow[t]{4}{*}{ Anxiety } & \multirow{4}{*}{$\begin{array}{l}\text { Whole review was CAYP: children } \\
\text { aged }<12\end{array}$} & \multirow[t]{4}{*}{ cCBT or iCBT } & 6 (1950 - August & \multirow[t]{4}{*}{6} \\
\hline & review and & study design & & & & and December & \\
\hline & meta- & & & & & 2013) & \\
\hline & analysis & & & & & & \\
\hline
\end{tabular}




\begin{tabular}{|c|c|c|c|c|c|c|c|}
\hline $\begin{array}{l}\text { Schlegl et } \\
\text { al. (2015) }\end{array}$ & $\begin{array}{l}\text { Systematic } \\
\text { review }\end{array}$ & $\begin{array}{l}\text { No restrictions on } \\
\text { study design }\end{array}$ & Eating disorders & $\begin{array}{l}\text { Review was with all populations: } \\
\text { separate reporting of CAYP } \\
\text { (adolescent) studies }\end{array}$ & Technology-based interventions & $\begin{array}{l}3 \text { CAYP-only studies } \\
\text { (up to August } \\
2014 \text { ) }\end{array}$ & 3 \\
\hline $\begin{array}{l}\text { Seko et al. } \\
\text { (2014) }\end{array}$ & $\begin{array}{l}\text { Scoping } \\
\text { review }\end{array}$ & $\begin{array}{l}\text { No restrictions on } \\
\text { study design }\end{array}$ & $\begin{array}{l}\text { Any mental health } \\
\text { condition }\end{array}$ & $\begin{array}{l}\text { Whole review was CAYP: } 13-24 \\
\text { years } \\
\text { Adolescents: } 13-18 \text { years } \\
\text { Young adults: } 19-24 \text { years) }\end{array}$ & Mobile-based interventions (e.g. SMS, apps) & $\begin{array}{l}17 \text { (up to June } \\
2013 \text { ) }\end{array}$ & $\mathrm{n} / \mathrm{a}$ \\
\hline $\begin{array}{l}\text { Siemer et } \\
\text { al. (2011) }\end{array}$ & $\begin{array}{l}\text { Systematic } \\
\text { review }\end{array}$ & Not defined & $\begin{array}{l}\text { Any mental health } \\
\text { condition }\end{array}$ & Whole review was CAYP & Internet-delivered interventions & $\begin{array}{l}20 \text { (date not } \\
\text { mentioned) }\end{array}$ & 3 \\
\hline $\begin{array}{l}\text { Ye et al. } \\
\text { (2014) }\end{array}$ & $\begin{array}{l}\text { Systematic } \\
\text { review and } \\
\text { meta- } \\
\text { analysis }\end{array}$ & $\begin{array}{l}\text { RCTs; RTs; Pre-Post } \\
\text { comparisons; } \\
\text { Observational studies }\end{array}$ & $\begin{array}{l}\text { Anxiety } \\
\text { Depression }\end{array}$ & $\begin{array}{l}\text { Whole review was CAYP: aged } \\
<25 \text { years, also included studies } \\
\text { targeting parents of children with } \\
\text { mental health-related issue }\end{array}$ & Internet-delivered interventions & $7(1990-2012)$ & 8 \\
\hline
\end{tabular}

*NB: The AMSTAR tool is used for assessing methodological quality of systematic reviews and meta-analyses only, and so were not performed for scoping reviews.

For systematic reviews without a meta-analysis: scores 0-3 indicates low quality, scores 4-7 moderate quality, and scores 8-9 high quality.

For systematic reviews with meta-analysis: scores 0-4 indicate low quality, 5-8 moderate quality, and 9-11 high quality. 
Table 3. Summary of the study characteristics of RCTs included in the updated systematic review

\begin{tabular}{|c|c|c|c|c|c|c|c|c|c|c|c|c|c|}
\hline \multirow[t]{2}{*}{ Study } & \multirow{2}{*}{$\begin{array}{c}\text { Trial } \\
\text { arms } \\
\text { and } \\
\text { sample } \\
\text { size }\end{array}$} & \multirow{2}{*}{$\begin{array}{c}\text { Age } \\
\text { range } \\
(\text { mean }) \\
\text { and } \\
\text { gender } \\
(\mathrm{nM} / \mathrm{nF})\end{array}$} & \multirow{2}{*}{$\begin{array}{c}\text { Target of } \\
\text { DHI }\end{array}$} & \multicolumn{4}{|c|}{ Intervention } & \multicolumn{4}{|c|}{ Comparator(s) } & \multirow{2}{*}{$\begin{array}{l}\text { Withdrawals } \\
\text { and dropout } \\
\text { at post- } \\
\text { intervention }\end{array}$} & \multirow{2}{*}{$\begin{array}{l}\text { ITT } \\
\text { analys } \\
\text { is }\end{array}$} \\
\hline & & & & Name & $\mathbf{N}$ & Frequency & $\begin{array}{l}\text { Location and } \\
\text { level of } \\
\text { support }\end{array}$ & Name & $\mathbf{N}$ & Frequency & $\begin{array}{l}\text { Location } \\
\text { and level of } \\
\text { support }\end{array}$ & & \\
\hline \multicolumn{14}{|c|}{$\begin{array}{l}\text { Attention Deficit Hyperactivity Disorder } \\
\text { (ADHD) } \\
\text { Neurofeedback training }\end{array}$} \\
\hline $\begin{array}{l}\text { Arnold et } \\
\text { al. (2013) }\end{array}$ & $\begin{array}{l}2 \text { arms } \\
\mathrm{N}=39\end{array}$ & $\begin{array}{l}6-12 \text { yrs } \\
(8.9) \\
31 / 8\end{array}$ & $\begin{array}{l}\text { Treatment: } \\
\text { participants } \\
\text { had } \\
\text { diagnosis of } \\
\text { ADHD }\end{array}$ & $\begin{array}{l}\text { SmartBrain }{ }^{\circledR} \\
\text { videogame } \\
\text { system }\end{array}$ & 26 & $\begin{array}{l}40 \times 45 \text { min } \\
\text { sessions, } \\
\text { either } 2 \text { or } 3 \\
\text { times weekly }\end{array}$ & $\begin{array}{l}\text { Unsure: states } \\
\text { participants did } \\
\text { not require a } \\
\text { "coach" }\end{array}$ & $\begin{array}{l}\text { Attention } \\
\text { Placebo }\end{array}$ & 13 & $\begin{array}{l}\text { Same as main } \\
\text { intervention }\end{array}$ & $\begin{array}{l}\text { Same as } \\
\text { main } \\
\text { intervention }\end{array}$ & $\begin{array}{l}\text { Intervention: } \\
\mathrm{n}=2 \text { ( } 1 \text { to } \\
\text { pursue } \\
\text { medication; } 1 \\
\text { due to distance } \\
\text { and grades) }\end{array}$ & No \\
\hline $\begin{array}{l}\text { Bink et al. } \\
(2014 \\
2015)\end{array}$ & $\begin{array}{l}2 \text { arms } \\
\mathrm{N}=90\end{array}$ & $\begin{array}{l}12-24 \\
\text { yrs } \\
(16.1) \\
90 / 0\end{array}$ & $\begin{array}{l}\text { Treatment: } \\
\text { participants } \\
\text { had } \\
\text { diagnosis of } \\
\text { ADHD }\end{array}$ & $\begin{array}{l}\text { Unnamed } \\
\text { neurofeedback } \\
\text { training } \\
\text { computer } \\
\text { program + TAU }\end{array}$ & 59 & $\begin{array}{l}\text { Up to } 40 x \\
30 \text { min } \\
\text { session, } \\
\text { either } 2 \text { or } 3 \\
\text { times a } \\
\text { week over } \\
\text { approx. } 25 \\
\text { weeks }\end{array}$ & $\begin{array}{l}\text { Within a clinic; } \\
\text { training was } \\
\text { delivered by } \\
\text { psychologist }\end{array}$ & TAU & 31 & $\begin{array}{l}\text { Varied by each } \\
\text { participant }\end{array}$ & $\begin{array}{l}\text { Dependent } \\
\text { on type of } \\
\text { TAU }\end{array}$ & $\begin{array}{l}\text { Comparator: } \\
\mathrm{n}=3 \text { (1 lost; } 2 \\
\text { to pursue } \\
\text { medication) } \\
\text { Intervention: } \\
\mathrm{n}=12 \text { ( } 9 \\
\text { discontinued; } \\
2 \text { moved } \\
\text { location; } 1 \text { for } \\
\text { medical } \\
\text { reasons) }\end{array}$ & No \\
\hline $\begin{array}{l}\text { Dongen- } \\
\text { Boomsma } \\
\text { et al. } \\
(2013)\end{array}$ & $\begin{array}{l}2 \text { arms } \\
\mathrm{N}=41\end{array}$ & $\begin{array}{l}8-15 \text { yrs } \\
(16.1) \\
34 / 7\end{array}$ & $\begin{array}{l}\text { Treatment: } \\
\text { participants } \\
\text { had } \\
\text { diagnosis of } \\
\text { ADHD }\end{array}$ & $\begin{array}{l}\text { BrainMaster } \\
\text { Atlantis } ₫\end{array}$ & 22 & $\begin{array}{l}30 \times 45 \mathrm{~min} \\
\text { sessions, } \\
\text { twice weekly }\end{array}$ & $\begin{array}{l}\text { Within a clinic: } \\
\text { neurofeedback } \\
\text { therapist } \\
\text { delivered } \\
\text { sessions }\end{array}$ & $\begin{array}{l}\text { Attention } \\
\text { Placebo }\end{array}$ & 19 & $\begin{array}{l}\text { Same as main } \\
\text { intervention }\end{array}$ & $\begin{array}{l}\text { Same as } \\
\text { main } \\
\text { intervention }\end{array}$ & $\begin{array}{l}\text { Comparator: } \\
\mathrm{n}=5 \text { (all } \\
\text { discontinued) } \\
\text { None }\end{array}$ & Yes \\
\hline
\end{tabular}




\begin{tabular}{|c|c|c|c|c|c|c|c|c|c|c|c|c|c|}
\hline $\begin{array}{l}\text { Li et al. } \\
\text { (2013) }\end{array}$ & $\begin{array}{l}2 \text { arms } \\
\mathrm{N}=64\end{array}$ & $\begin{array}{l}7-16 \text { yrs } \\
(10.6) \\
54 / 10\end{array}$ & $\begin{array}{l}\text { Treatment: } \\
\text { participants } \\
\text { had } \\
\text { diagnosis of } \\
\text { ADHD }\end{array}$ & $\begin{array}{l}\text { Unnamed } \\
\text { neurofeedback } \\
\text { training } \\
\text { computer } \\
\text { program plus } \\
\text { methyl- } \\
\text { phenidate } \\
\text { medication }\end{array}$ & 32 & $\begin{array}{l}40 \times 25-35 \\
\text { min } \\
\text { sessions, } 2 \\
\text { to } 5 \text { times } \\
\text { weekly }\end{array}$ & $\begin{array}{l}\text { Unsure where } \\
\text { training took } \\
\text { place }\end{array}$ & $\begin{array}{l}\text { Attention } \\
\text { placebo plus } \\
\text { methyl- } \\
\text { phenidate } \\
\text { medication }\end{array}$ & 32 & $\begin{array}{l}\text { Same as main } \\
\text { intervention }\end{array}$ & $\begin{array}{l}\text { Same as } \\
\text { main } \\
\text { intervention }\end{array}$ & $\begin{array}{l}\text { Intervention: } \\
\mathrm{n}=1 \\
\text { Comparator: } \\
\mathrm{n}=3\end{array}$ & Unsure \\
\hline $\begin{array}{l}\text { Steiner et } \\
\text { al. (2014) }\end{array}$ & $\begin{array}{l}3 \text { arms } \\
\mathrm{N}=104\end{array}$ & $\begin{array}{l}7-11 \text { yrs } \\
(8.56) \\
77 / 27\end{array}$ & $\begin{array}{l}\text { Treatment: } \\
\text { participants } \\
\text { had } \\
\text { diagnosis of } \\
\text { ADHD }\end{array}$ & 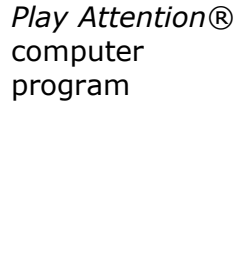 & 34 & $\begin{array}{l}40 \times 45 \text { min } \\
\text { sessions, } 3 \\
\text { times a } \\
\text { week over } 5 \\
\text { months }\end{array}$ & $\begin{array}{l}\text { In school: } \\
\text { monitored by } \\
\text { research } \\
\text { assistant }\end{array}$ & $\begin{array}{l}\text { 1) Captain's } \\
\text { Log } \\
\text { cognitive } \\
\text { training } \\
\text { computer } \\
\text { program } \\
\text { 2) TAU }\end{array}$ & $\begin{array}{l}\text { 1) } \\
34 \\
\text { 2) } \\
36\end{array}$ & $\begin{array}{l}\text { 1) Same as } \\
\text { main } \\
\text { intervention } \\
\text { 2) Dependent } \\
\text { on participants }\end{array}$ & $\begin{array}{l}\text { 1) Same as } \\
\text { main } \\
\text { intervention } \\
\text { 2) } \\
\text { Dependent } \\
\text { on TAU }\end{array}$ & $\begin{array}{l}\text { Cognitive } \\
\text { training } \\
\text { comparator: } \\
\mathrm{n}=2\end{array}$ & Yes \\
\hline Working $n$ & emory tr & ing & & & & & & & & & & & \\
\hline $\begin{array}{l}\text { Chacko et } \\
\text { al. (2014) }\end{array}$ & $\begin{array}{l}2 \text { arms } \\
\mathrm{N}=85\end{array}$ & $\begin{array}{l}7-11 \text { yrs } \\
(8.4) \\
66 / 19\end{array}$ & $\begin{array}{l}\text { Treatment: } \\
\text { participants } \\
\text { had } \\
\text { diagnosis of } \\
\text { ADHD }\end{array}$ & $\begin{array}{l}\text { CogMed } R M \otimes \\
\text { computer } \\
\text { program }\end{array}$ & 44 & $\begin{array}{l}25 \times 30-45 \\
\text { min } \\
\text { sessions, } \\
\text { over } 5 \\
\text { days/weekly } \\
\text { over } 5 \\
\text { weeks }\end{array}$ & $\begin{array}{l}\text { Participants' } \\
\text { home: } \\
\text { supervised by } \\
\text { training aide } \\
\text { (parent or } \\
\text { guardian) with } \\
\text { weekly phone } \\
\text { calls from coach }\end{array}$ & $\begin{array}{l}\text { Attention } \\
\text { Placebo }\end{array}$ & 41 & $\begin{array}{l}\text { Same as main } \\
\text { intervention }\end{array}$ & $\begin{array}{l}\text { Same as } \\
\text { main } \\
\text { intervention }\end{array}$ & $\begin{array}{l}\text { Intervention: } \\
n=3 \\
\text { discontinued; } \\
n=3 \text { parents, } \\
n=4 \text { children }+ \\
n=4 \text { teachers } \\
\text { lost to follow- } \\
\text { up } \\
\text { Comparator: } \\
n=1 \\
\text { discontinued; } \\
n=4 \text { parents, } \\
n=5 \text { children }+ \\
n=1 \text { teachers } \\
\text { lost to follow- } \\
\text { up }\end{array}$ & Yes \\
\hline $\begin{array}{l}\text { Dongen- } \\
\text { Boomsma } \\
\text { et al. } \\
(2014)\end{array}$ & $\begin{array}{l}2 \text { arms } \\
\mathrm{N}=51\end{array}$ & $\begin{array}{l}5-7 \text { yrs } \\
(6.55) \\
34 / 13\end{array}$ & $\begin{array}{l}\text { Treatment: } \\
\text { participants } \\
\text { had } \\
\text { diagnosis of } \\
\text { ADHD }\end{array}$ & $\begin{array}{l}\text { CogMed JM® } \\
\text { computer } \\
\text { program }\end{array}$ & 27 & $\begin{array}{l}25 \times 15 \text { min } \\
\text { sessions, } \\
\text { over } 5 \text { days } \\
\text { per week }\end{array}$ & $\begin{array}{l}\text { Completed in } \\
\text { participants' } \\
\text { home }\end{array}$ & $\begin{array}{l}\text { Attention } \\
\text { Placebo }\end{array}$ & 24 & $\begin{array}{l}\text { Same as main } \\
\text { intervention }\end{array}$ & $\begin{array}{l}\text { Same as } \\
\text { main } \\
\text { intervention }\end{array}$ & $\begin{array}{l}\text { Intervention: } \\
\mathrm{n}=1 \\
\text { (discontinued) } \\
\text { Comparator: } \\
\mathrm{n}=3 \\
\text { (discontinued) }\end{array}$ & No \\
\hline
\end{tabular}




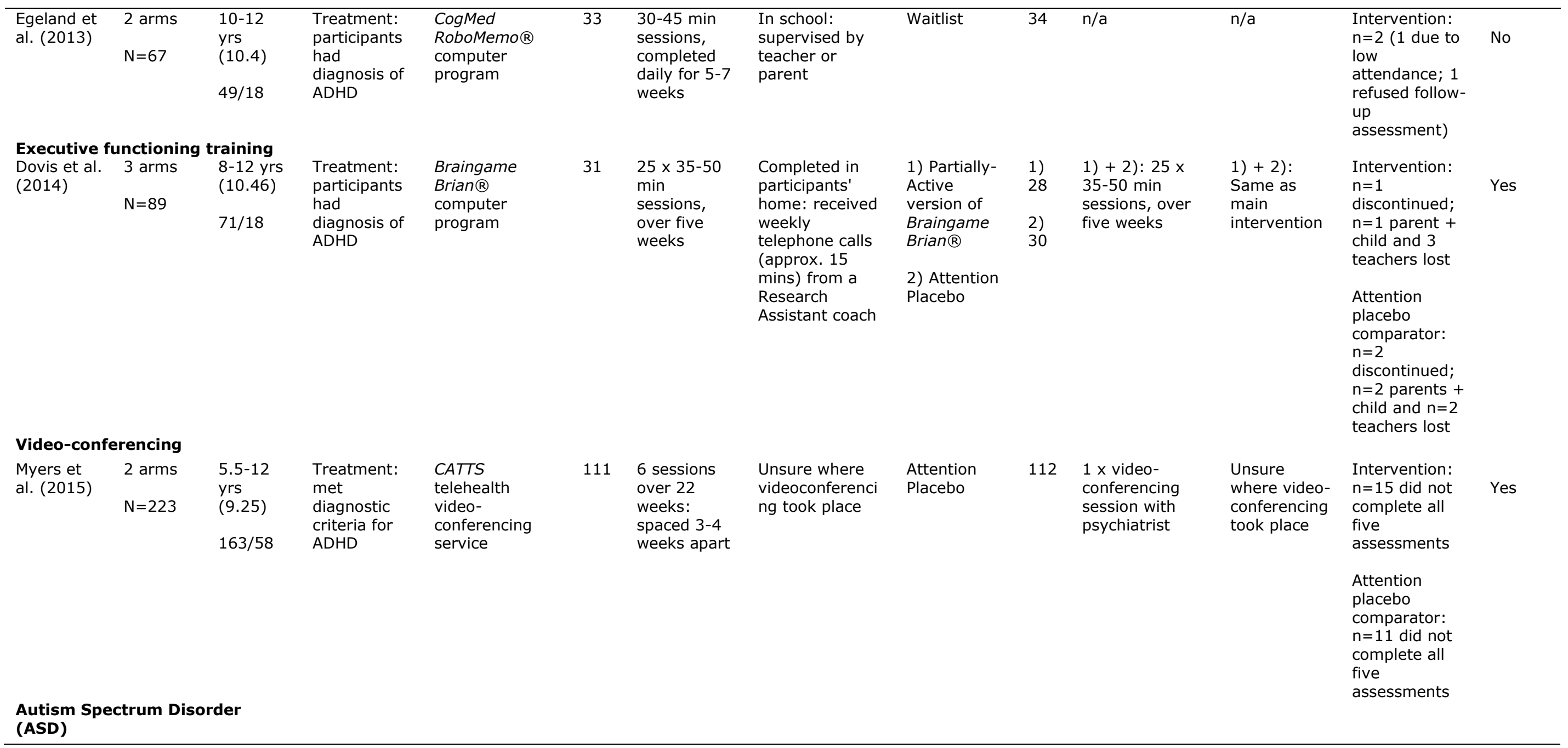




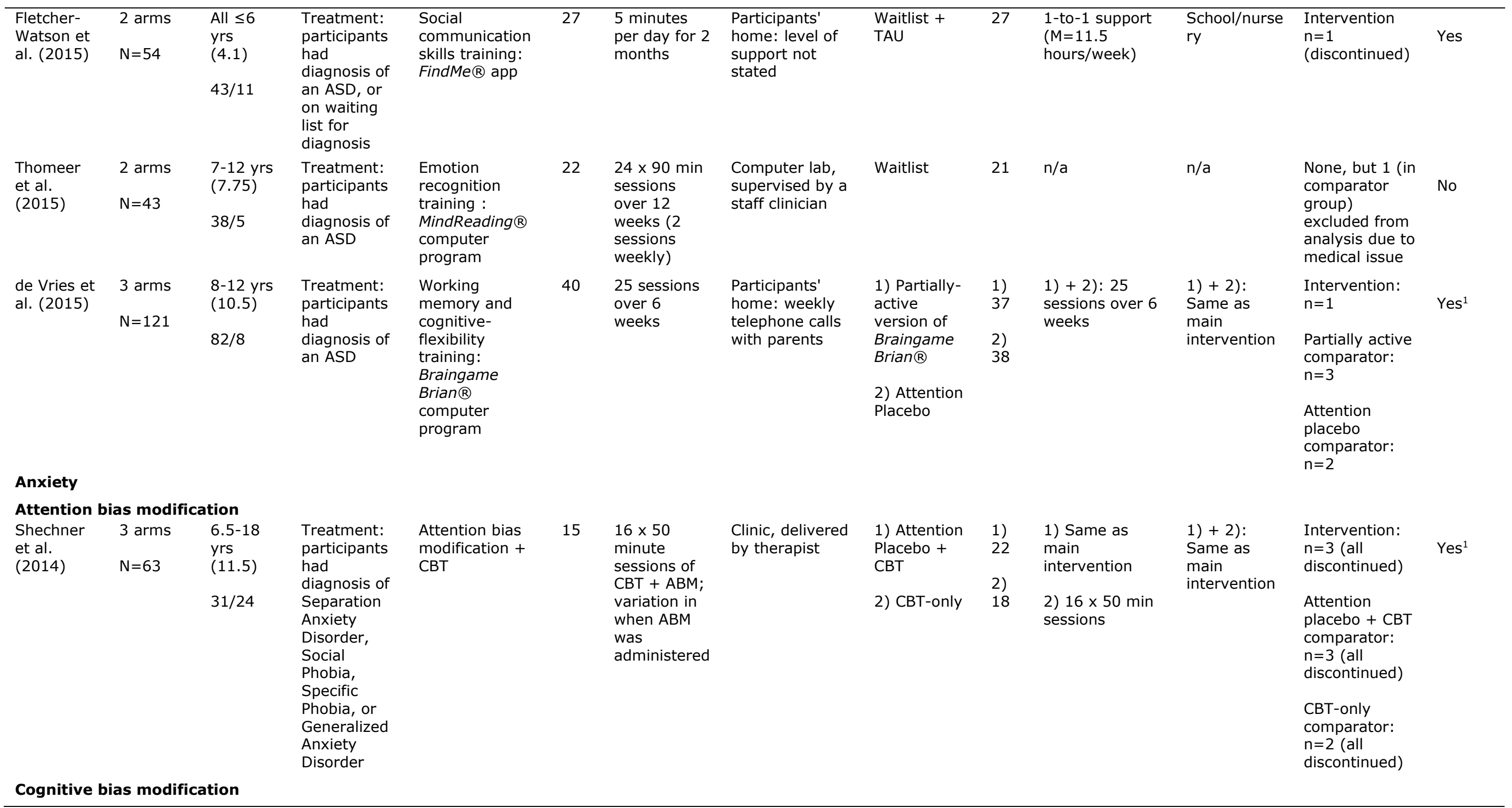




\begin{tabular}{|c|c|c|c|c|c|c|c|c|c|c|c|c|c|}
\hline $\begin{array}{l}\text { Sportel et } \\
\text { al. (2013) }\end{array}$ & $\begin{array}{l}3 \text { arms } \\
\mathrm{N}=240\end{array}$ & $\begin{array}{l}12-15 \\
\text { yrs } \\
(14) \\
64 / 176\end{array}$ & $\begin{array}{l}\text { Prevention: } \\
\text { Participants } \\
\text { scored } \\
\text { above } \\
\text { threshold for } \\
\text { social or test } \\
\text { anxiety }\end{array}$ & $\begin{array}{l}\text { Cognitive bias } \\
\text { modification }\end{array}$ & 86 & $\begin{array}{l}20 \times 40 \mathrm{~min} \\
\text { sessions, } \\
\text { twice a week }\end{array}$ & $\begin{array}{l}\text { Delivered } \\
\text { online, accessed } \\
\text { in participants' } \\
\text { own location }\end{array}$ & $\begin{array}{l}\text { 1) In-class } \\
\text { group CBT } \\
\text { 2) No } \\
\text { treatment } \\
\text { control }\end{array}$ & $\begin{array}{l}\text { 1) } \\
84 \\
2) \\
70\end{array}$ & $\begin{array}{l}\text { 1) } 20 \times 40 \mathrm{~min} \\
\text { sessions, twice } \\
\text { a week } \\
\text { 2) N/A }\end{array}$ & $\begin{array}{l}\text { 1) In school } \\
\text { 2) N/A }\end{array}$ & $\begin{array}{l}\text { Intervention: } \\
\mathrm{n}=40 \\
\text { discontinued; } \\
\mathrm{n}=13 \text { quit } \\
\text { participation } \\
\mathrm{CBT} \\
\text { comparator: } \\
\mathrm{n}=20 \\
\text { discontinued; } \\
\mathrm{n}=15 \text { quit } \\
\text { participation } \\
\text { No treatment } \\
\text { comparator: } \\
\mathrm{n}=12 \text { quit } \\
\text { participation }\end{array}$ & Yes \\
\hline \multicolumn{14}{|c|}{ eCBT interventions } \\
\hline $\begin{array}{l}\text { Storch et } \\
\text { al. (2015) }\end{array}$ & $\begin{array}{l}2 \text { arms } \\
\mathrm{N}=100\end{array}$ & $\begin{array}{l}7-13 \text { yrs } \\
(9.8) \\
56 / 44\end{array}$ & $\begin{array}{l}\text { Treatment: } \\
\text { participants } \\
\text { had } \\
\text { Diagnosis of } \\
\text { Separation } \\
\text { Anxiety } \\
\text { Disorder, } \\
\text { Social } \\
\text { Phobia, } \\
\text { Generalized } \\
\text { Anxiety } \\
\text { Disorder, } \\
\text { Specific } \\
\text { Phobia, or } \\
\text { Panic } \\
\text { Disorder }\end{array}$ & $\begin{array}{l}\text { Camp Cope-A- } \\
\text { Lot in-person } \\
\text { support and } \\
\text { CCBT program }\end{array}$ & 49 & $\begin{array}{l}12 \times 50-60 \\
\text { min } \\
\text { sessions, } \\
\text { delivered } \\
\text { weekly }\end{array}$ & $\begin{array}{l}\text { Health centre: } \\
\text { first } 6 \text { sessions } \\
\text { primarily } \\
\text { computer- } \\
\text { based; final } 6 \\
\text { sessions } \\
\text { therapist led }\end{array}$ & TAU & 51 & $\begin{array}{l}\text { Dependent on } \\
\text { TAU }\end{array}$ & $\begin{array}{l}\text { Dependent } \\
\text { on type of } \\
\text { TAU }\end{array}$ & $\begin{array}{l}\text { Intervention: } \\
\mathrm{n}=4 \\
\text { Comparator: } \\
\mathrm{n}=4\end{array}$ & Yes \\
\hline
\end{tabular}




\begin{tabular}{|c|c|c|c|c|c|c|c|c|c|c|c|c|c|}
\hline $\begin{array}{l}\text { Vigerland } \\
\text { et al. } \\
\text { (2016) }\end{array}$ & $\begin{array}{l}2 \text { arms } \\
\mathrm{N}=93\end{array}$ & $\begin{array}{l}8-12 \text { yrs } \\
(10) \\
38 / 55\end{array}$ & $\begin{array}{l}\text { Treatment: } \\
\text { participants } \\
\text { had } \\
\text { diagnosis of } \\
\text { Separation } \\
\text { Anxiety } \\
\text { Disorder, } \\
\text { Social } \\
\text { Phobia, } \\
\text { Generalized } \\
\text { Anxiety } \\
\text { Disorder, } \\
\text { Specific } \\
\text { Phobia, or } \\
\text { Panic } \\
\text { Disorder }\end{array}$ & $\begin{array}{l}\text { Unnamed cCBT } \\
\text { parent-child } \\
\text { program }\end{array}$ & 46 & $\begin{array}{l}\text { Completed } \\
\text { at own pace; } \\
\text { participants } \\
\text { were given } \\
\text { access for } \\
10 \text { weeks }\end{array}$ & $\begin{array}{l}\text { Online and } \\
\text { accessed at } \\
\text { home: online } \\
\text { contact with } \\
\text { therapist and } 3 \\
\text { telephone calls }\end{array}$ & Waitlist & 47 & $\mathrm{~N} / \mathrm{A}$ & $\mathrm{N} / \mathrm{A}$ & $\begin{array}{l}\text { Intervention: } \\
\mathrm{n}=2 \text { no } \\
\text { primary } \\
\text { outcome } \\
\text { measure data; } \\
\mathrm{n}=5 \text { children } \\
\text { and } \mathrm{n}=4 \\
\text { parents did not } \\
\text { complete } \\
\text { secondary } \\
\text { measure } \\
\text { Comparator: } \\
\mathrm{n}=1 \text { no } \\
\text { primary } \\
\text { outcome } \\
\text { measure data; } \\
\mathrm{n}=15 \text { children } \\
\text { and } \mathrm{n}=13 \\
\text { parents did not } \\
\text { complete } \\
\text { secondary } \\
\text { measure }\end{array}$ & Unsure \\
\hline \multicolumn{14}{|l|}{ Depression } \\
\hline \multicolumn{14}{|c|}{ Attention bias modification } \\
\hline $\begin{array}{l}\text { Yang et al. } \\
\text { (2014) }\end{array}$ & $\begin{array}{l}3 \text { arms } \\
N=77\end{array}$ & $\begin{array}{l}18-22 \\
\text { yrs } \\
(19.4) \\
22 / 55\end{array}$ & $\begin{array}{l}\text { Prevention: } \\
\text { participants } \\
\text { screened for } \\
\text { mild, } \\
\text { moderate or } \\
\text { severe } \\
\text { depression } \\
\text { symptoms }\end{array}$ & $\begin{array}{l}\text { Attention bias } \\
\text { modification }\end{array}$ & 27 & $\begin{array}{l}8 \times \text { approx. } \\
12 \text { minute } \\
\text { sessions: } 4 \\
\text { sessions } \\
\text { each week } \\
\text { over } 2 \\
\text { weeks }\end{array}$ & $\begin{array}{l}\text { Laboratory; } \\
\text { unsure of level } \\
\text { of human } \\
\text { support/input }\end{array}$ & $\begin{array}{l}\text { 1) Attention } \\
\text { Placebo } \\
\text { 2) No } \\
\text { intervention }\end{array}$ & $\begin{array}{l}\text { 1) } \\
27 \\
\text { 2) } \\
23\end{array}$ & $\begin{array}{l}\text { 1) Same as } \\
\text { main } \\
\text { intervention } \\
\text { 2) N/A }\end{array}$ & $\begin{array}{l}\text { 1) Same as } \\
\text { main } \\
\text { intervention } \\
\text { 2) N/A }\end{array}$ & $\begin{array}{l}\text { None: all } \\
\text { completed } \\
\text { post- } \\
\text { intervention } \\
\text { assessment }\end{array}$ & Yes \\
\hline \multicolumn{14}{|c|}{ Solution-Focused Brief Therapy } \\
\hline $\begin{array}{l}\text { Kramer et } \\
\text { al. (2014) }\end{array}$ & $\begin{array}{l}2 \text { arms } \\
N=263\end{array}$ & $\begin{array}{l}12-22 \\
\text { yrs } \\
(19.5) \\
56 / 207\end{array}$ & $\begin{array}{l}\text { Prevention: } \\
\text { participants } \\
\text { had elevated } \\
\text { depression } \\
\text { symptoms }\end{array}$ & $\begin{array}{l}\text { PratenOnline } \\
\text { chatroom-based } \\
\text { Solution- } \\
\text { Focused Brief } \\
\text { Therapy (SFBT) } \\
\text { with healthcare } \\
\text { professional }\end{array}$ & 131 & $\begin{array}{l}\text { Each chat } \\
\text { approx. } 60 \\
\text { mins. } \\
\text { Number of } \\
\text { chats limited } \\
\text { to } 5\end{array}$ & $\begin{array}{l}\text { Online: } \\
\text { participants } \\
\text { accessed chat in } \\
\text { own } \\
\text { environment }\end{array}$ & $\begin{array}{l}\text { Waitlist } \\
\text { control }\end{array}$ & 132 & $\mathrm{~N} / \mathrm{A}$ & N/A & $\begin{array}{l}\text { Intervention: } \\
\mathrm{n}=56 \text { did not } \\
\text { complete post- } \\
\text { intervention } \\
\text { measures } \\
\\
\text { Comparator: } \\
\mathrm{n}=55 \text { did not } \\
\text { complete post- }\end{array}$ & Yes $^{1}$ \\
\hline
\end{tabular}


intervention

measures

eCBT interventions

Lillevoll

$\begin{array}{llll}4 \text { arms } & \begin{array}{l}15-20 \\ \text { yrs }\end{array} & \begin{array}{l}\text { Universal: } \\ \text { no mental } \\ \text { health- } \\ \text { related } \\ \text { inclusion } \\ \text { criteria }\end{array} & \begin{array}{l}\text { MoodGym cCBT } \\ \text { with 3 arms of } \\ \text { email } \\ \text { reminders: }\end{array} \\ \begin{array}{lll}\text { (16.8) No emails } \\ \text { 2) Standard } \\ \text { emails }\end{array} \\ & 335 / 440 & \begin{array}{l}\text { 3) Tailored } \\ \text { emails }\end{array}\end{array}$

1) 5 modules

Online and

$\begin{array}{ll}\text { (each } & \text { completed in } \\ \text { approx. 30- } & \text { participants' }\end{array}$

control

180

N/A

own

17645 mins),

environment,

175 own pace self-guided but

with three

different levels

of email

reminders

$\begin{array}{llll}\begin{array}{l}\text { Smith et al. } \\ \text { (2015) }\end{array} & 2 \text { arms } & \begin{array}{l}12-16 \\ \text { yrs }\end{array} & \begin{array}{l}\text { Prevention: } \\ \text { participants } \\ \text { had elevated } \\ \text { depression }\end{array} \\ & \mathrm{N}=112 & \mathrm{~N} / \mathrm{S}) & \begin{array}{l}\text { symptoms } \\ \text { s/S }\end{array}\end{array}$

StressBusters
CCBT

55

$\begin{array}{ll}8 \text { sessions } & \text { Computer- } \\ \text { (approx. } 45 & \text { based, } \\ \text { mins each), } & \text { completed in } \\ \text { over } 8 & \text { school }\end{array}$

weeks

school

$$
\text { TAU }
$$

Intervention:

$\mathrm{n}=158$ did not No

complete

follow-up

measures

Comparator:

$\mathrm{n}=46$ did not

complete

follow-up

measures

Comparator

$\mathrm{n}=2$ not

assessed at

post-

intervention

$\begin{array}{lllllll}\begin{array}{l}\text { Stasiak et } \\ \text { al. (2014) }\end{array} & 2 \text { arms } & \begin{array}{l}13-18 \\ \text { yrs }\end{array} & \begin{array}{l}\text { Prevention: } \\ \text { participants } \\ \text { had elevated } \\ \text { depression } \\ \text { symptoms }\end{array} & \begin{array}{l}\text { The Journey } \\ \text { cCBT }\end{array} & 17 \begin{array}{l}7 \text { modules } \\ \text { (each 25-30 } \\ \text { mins each) } \\ \text { completed } \\ \text { over 4-10 } \\ \text { weeks }\end{array} & \begin{array}{l}\text { Completed at } \\ \text { school with } \\ \text { minimal } \\ \text { oversight from } \\ \text { counsellors }\end{array}\end{array}$
intervention

Same as

main

Intervention: $\mathrm{n}=1$ withdrew from study

Comparator:

$\mathrm{n}=1$ did not

complete

assessment;

$\mathrm{n}=3$ withdrew

from study 


\begin{tabular}{|c|c|c|c|c|c|c|c|c|c|c|c|c|c|}
\hline $\begin{array}{l}\text { Saulsberry } \\
\text { et al. } \\
\text { (2013) }\end{array}$ & $\begin{array}{l}2 \text { arms } \\
N=84\end{array}$ & $\begin{array}{l}14-21 \\
\text { yrs } \\
(17.39) \\
36 / 47\end{array}$ & $\begin{array}{l}\text { Prevention: } \\
\text { participants } \\
\text { had } \\
\text { persistent } \\
\text { subthreshold } \\
\text { depression }\end{array}$ & $\begin{array}{l}\text { Motivational } \\
\text { interview (MI) } \\
\text { with primary } \\
\text { care practitioner } \\
+ \text { CATCH-IT } \\
\text { internet-based } \\
\text { program (based } \\
\text { on CBT, } \\
\text { humanistic and } \\
\text { interpersonal } \\
\text { training } \\
\text { principles) }\end{array}$ & 40 & $\begin{array}{l}\text { Primary care } \\
\text { practitioner } \\
\text { helps } \\
\text { participant } \\
\text { develop } \\
\text { cost-benefit } \\
\text { assessment } \\
\text { towards } \\
\text { completing } \\
\text { CATCH-IT }\end{array}$ & $\begin{array}{l}\text { MI was in } \\
\text { primary care, } \\
\text { but accessed } \\
\text { CATCH-IT in } \\
\text { own location; } 3 \\
\text { motivational } \\
\text { telephone calls } \\
\text { from social } \\
\text { worker case } \\
\text { managers }\end{array}$ & $\begin{array}{l}\text { Brief Advice } \\
\text { with primary } \\
\text { care } \\
\text { practitioner } \\
+ \text { CATCH-IT }\end{array}$ & 43 & $\begin{array}{l}\text { In initial } \\
\text { consultation, } \\
\text { primary care } \\
\text { practitioner } \\
\text { refers } \\
\text { participant to } \\
\text { CATCH-IT }\end{array}$ & $\begin{array}{l}\text { BA (in initial } \\
\text { consultation) } \\
\text { was in } \\
\text { primary } \\
\text { care, but } \\
\text { accessed } \\
\text { CATCH-IT in } \\
\text { own location }\end{array}$ & $\begin{array}{l}\text { Intervention: } \\
\mathrm{n}=6 \text { lost; } \mathrm{n}=2 \\
\text { withdrew; } \mathrm{n}=2 \\
\text { dis-enrolled; } \\
\mathrm{n}=1 \text { died } \\
\\
\text { Comparator: } \\
\mathrm{n}=7 \text { lost; } \mathrm{n}=1 \\
\text { withdrew; } \mathrm{n}=1 \\
\text { dis-enrolled as } \\
\text { did not meet } \\
\text { criteria }\end{array}$ & Yes \\
\hline \multicolumn{14}{|c|}{$\begin{array}{l}\text { Anxiety and depression } \\
\text { eCBT interventions }\end{array}$} \\
\hline $\begin{array}{l}\text { Melnyk et } \\
\text { al. (2015) }\end{array}$ & $\begin{array}{l}2 \text { arms } \\
\mathrm{N}=121\end{array}$ & $\begin{array}{l}\text { N/S } \\
(18.5) \\
19 / 102\end{array}$ & $\begin{array}{l}\text { Universal: } \\
\text { no mental } \\
\text { health- } \\
\text { related } \\
\text { inclusion } \\
\text { criteria }\end{array}$ & $\begin{array}{l}\text { Creating } \\
\text { Opportunities } \\
\text { for Personal } \\
\text { Empowerment } \\
\left(' C O P E^{\prime}\right) \text { cCBT }\end{array}$ & 82 & $\begin{array}{l}7 \text { Modules } \\
\text { (approx. } 30 \\
\text { mins each). } \\
\text { Unsure how } \\
\text { long } \\
\text { participants } \\
\text { had to } \\
\text { access COPE }\end{array}$ & $\begin{array}{l}\text { Online was self- } \\
\text { guided, and } \\
\text { modules were } \\
\text { made available } \\
\text { sequentially }\end{array}$ & $\begin{array}{l}\text { Teaching-as- } \\
\text { usual }\end{array}$ & 39 & $\begin{array}{l}\text { Equal duration } \\
\text { to main } \\
\text { intervention }\end{array}$ & Self-guided & Not stated & Unsure \\
\hline $\begin{array}{l}\text { Sethi } \\
(2013)\end{array}$ & $\begin{array}{l}4 \text { arms } \\
\mathrm{N}=89\end{array}$ & $\begin{array}{l}18-25 \\
\text { yrs } \\
(20.8) \\
37 / 52\end{array}$ & $\begin{array}{l}\text { Prevention: } \\
\text { participants } \\
\text { had mild to } \\
\text { moderate } \\
\text { anxiety } \\
\text { symptoms } \\
\text { and / or } \\
\text { depression } \\
\text { symptoms }\end{array}$ & $\begin{array}{l}\text { MoodGym + FtF } \\
\text { CBT }\end{array}$ & 22 & $\begin{array}{l}5 \times \text { approx. } \\
60 \text { min } \\
\text { sessions, } \\
\text { delivered } \\
\text { weekly (first } \\
\text { and last } \\
\text { sessions } \\
\text { were } 90 \\
\text { mins) over } 5 \\
\text { weeks }\end{array}$ & $\begin{array}{l}\text { Completed at } \\
\text { youth centre or } \\
\text { university and } \\
\text { delivered in } \\
\text { private rooms }\end{array}$ & $\begin{array}{l}\text { 1) FtF CBT } \\
\text { 2) MoodGym } \\
\text { 3) No } \\
\text { intervention }\end{array}$ & $\begin{array}{l}\text { 1) } \\
21 \\
\text { 2) } \\
23 \\
3) \\
23\end{array}$ & $\begin{array}{l}\text { 1) and 2): } \\
\text { Same as main } \\
\text { intervention } \\
\text { 3) N/A }\end{array}$ & $\begin{array}{l}\text { 1) FtF CBT } \\
\text { delivered by } \\
\text { psychologist } \\
\text {; same as } \\
\text { main } \\
\text { intervention } \\
\text { 2) Same as } \\
\text { main } \\
\text { intervention }\end{array}$ & None & Yes \\
\hline & & & & & & & & & & & 3) $N / A$ & & \\
\hline
\end{tabular}




\begin{tabular}{|c|c|c|c|c|c|c|c|c|c|c|c|c|c|}
\hline $\begin{array}{l}\text { Wong et al. } \\
\text { (2014) }\end{array}$ & $\begin{array}{l}3 \text { arms } \\
\mathrm{N}=976\end{array}$ & $\begin{array}{l}14-16 \\
\text { yrs (N/S) } \\
293 / 683\end{array}$ & $\begin{array}{l}\text { Universal: } \\
\text { no mental } \\
\text { health- } \\
\text { related } \\
\text { inclusion } \\
\text { criteria }\end{array}$ & $\begin{array}{l}\text { ThisWayUp } \\
\text { Schools: } \\
\text { Combating } \\
\text { Depression and } \\
\text { Overcoming } \\
\text { Anxiety } \\
\text { Two arms: } \\
\text { 1) Received } \\
\text { 'anxiety' course } \\
\text { 2) Received } \\
\text { 'depression' } \\
\text { course }\end{array}$ & $\begin{array}{l}\text { 1) } \\
372 \\
\text { 2) } \\
380\end{array}$ & $\begin{array}{l}\text { One session } \\
\text { ( } 40 \text { mins } \\
\text { each) } \\
\text { completed } \\
\text { once a week } \\
\text { over 6-7 } \\
\text { weeks }\end{array}$ & $\begin{array}{l}\text { Delivered in } \\
\text { schools: second } \\
\text { half of session } \\
\text { involved } \\
\text { teachers } \\
\text { handing out } \\
\text { worksheets to } \\
\text { discuss and } \\
\text { reinforce } \\
\text { information } \\
\text { from ThisWayUp }\end{array}$ & $\begin{array}{l}\text { Teaching-as- } \\
\text { usual }\end{array}$ & 224 & $\begin{array}{l}\text { Not stated: } \\
\text { assume it was } \\
\text { weekly }\end{array}$ & $\begin{array}{l}\text { In school } \\
\text { with regular } \\
\text { teacher }\end{array}$ & $\begin{array}{l}555 \text { did not } \\
\text { complete post- } \\
\text { intervention } \\
\text { assessments } \\
\text { Due to loss of } \\
\text { data/data } \\
\text { corruption, } \\
\text { post- } \\
\text { intervention } \\
\text { data only } \\
\text { available for } \\
265 \\
\text { participants }\end{array}$ & Unsure \\
\hline \multicolumn{14}{|c|}{ Eating disorders } \\
\hline $\begin{array}{l}\text { Kass et al. } \\
\text { (2014) }\end{array}$ & $\begin{array}{l}2 \text { arms } \\
\mathrm{N}=151\end{array}$ & $\begin{array}{l}18-25 \\
\text { yrs } \\
(21) \\
0 / 151\end{array}$ & $\begin{array}{l}\text { Prevention: } \\
\text { participants } \\
\text { had as high } \\
\text { risk for } \\
\text { eating } \\
\text { disorder }\end{array}$ & $\begin{array}{l}\text { Student Bodies } \\
\text { coupled with } \\
\text { moderated } \\
\text { online } \\
\text { discussion group }\end{array}$ & 74 & $\begin{array}{l}8 \text { modules; } \\
\text { each module } \\
\text { released } \\
\text { weekly over } \\
8 \text { weeks }\end{array}$ & $\begin{array}{l}\text { Online and } \\
\text { completed in } \\
\text { own } \\
\text { environment; } \\
\text { discussion group } \\
\text { was guided by a } \\
\text { research } \\
\text { assistant and } \\
\text { clinician }\end{array}$ & $\begin{array}{l}\text { Student } \\
\text { Bodies } \\
\text { without } \\
\text { online } \\
\text { discussion } \\
\text { group }\end{array}$ & 77 & $\begin{array}{l}\text { Same as } \\
\text { intervention }\end{array}$ & None & $\begin{array}{l}\text { Intervention: } \\
\mathrm{n}=5 \text { never } \\
\text { logged into } \\
\text { intervention; } \\
\mathrm{n}=17 \text { did not } \\
\text { complete post- } \\
\text { intervention } \\
\text { assessments } \\
\text { Comparator: } \\
\mathrm{n}=2 \text { dropped } \\
\text { out; } \mathrm{n}=1 \\
\text { never logged } \\
\text { into } \\
\text { comparator; } \\
\mathrm{n}=15 \text { did not } \\
\text { complete post- } \\
\text { intervention } \\
\text { assessments }\end{array}$ & Yes \\
\hline $\begin{array}{l}\text { Saekow et } \\
\text { al. (2015) }\end{array}$ & $\begin{array}{l}2 \text { arms } \\
N=65\end{array}$ & $\begin{array}{l}18-25 \\
\text { yrs } \\
(N / S) \\
0 / 65\end{array}$ & $\begin{array}{l}\text { Prevention: } \\
\text { participants } \\
\text { screened as } \\
\text { having } \\
\text { subclinical } \\
\text { anorexia } \\
\text { nervosa, } \\
\text { bulimia } \\
\text { nervosa, } \\
\text { binge eating }\end{array}$ & Student Bodies & 31 & $\begin{array}{l}10 \text { modules; } \\
\text { each module } \\
\text { released } \\
\text { weekly over } \\
10 \text { weeks, } \\
\text { with a } \\
\text { booster } \\
\text { session } \\
\text { offered at } 2\end{array}$ & $\begin{array}{l}\text { Online and } \\
\text { completed in } \\
\text { own } \\
\text { environment; all } \\
\text { activities } \\
\text { reviewed by } \\
\text { coaches and } \\
\text { addressed in } \\
\text { weekly feedback } \\
\text { to participants }\end{array}$ & $\begin{array}{l}\text { Waitlist } \\
\text { control }\end{array}$ & 34 & $\mathrm{n} / \mathrm{a}$ & $\mathrm{n} / \mathrm{a}$ & $\begin{array}{l}\text { Intervention: } \\
\mathrm{n}=6 \text { lost to } \\
\text { follow-up; } \mathrm{n}=6 \\
\text { discontinued } \\
\text { Comparator: } \\
\mathrm{n}=7 \text { lost to } \\
\text { follow-up }\end{array}$ & Yes $^{1}$ \\
\hline
\end{tabular}




$\begin{array}{ll}\text { disorder, or } & \text { months after } \\ \text { purging } & \text { final module }\end{array}$

\section{Psychosis}

\begin{tabular}{|c|c|c|c|c|c|c|c|c|c|c|c|c|c|}
\hline $\begin{array}{l}\text { Holzer et al. } \\
\text { (2014) }\end{array}$ & $\begin{array}{l}2 \text { arms } \\
\mathrm{N}=32\end{array}$ & $\begin{array}{l}13-18 \\
\text { yrs } \\
(15.4) \\
18 / 14\end{array}$ & $\begin{array}{l}\text { Treatment: } \\
\text { participants } \\
\text { had } \\
\text { diagnosis of } \\
\text { psychotic } \\
\text { disorder, or } \\
\text { screened as } \\
\text { high risk of } \\
\text { psychosis }\end{array}$ & $\begin{array}{l}\text { Captain's Log: } \\
\text { computer- } \\
\text { assisted } \\
\text { cognitive } \\
\text { remediation } \\
\text { software }\end{array}$ & 18 & $\begin{array}{l}16 \times 45 \mathrm{~min} \\
\text { sessions, } 2 \\
\text { per week } \\
\text { over } 8 \\
\text { weeks }\end{array}$ & $\begin{array}{l}\text { Monitored } \\
\text { setting with } \\
\text { research } \\
\text { psychologist }\end{array}$ & $\begin{array}{l}\text { Attention } \\
\text { Placebo }\end{array}$ & 14 & $\begin{array}{l}16 \times 30 \text { min } \\
\text { sessions, } 2 \text { per } \\
\text { week over } 8 \\
\text { weeks }\end{array}$ & $\begin{array}{l}\text { Same as } \\
\text { main } \\
\text { intervention }\end{array}$ & $\begin{array}{l}\text { Intervention: } \\
\mathrm{n}=3 \\
\text { discontinued } \\
\text { Comparator: } \\
\mathrm{n}=1 \\
\text { discontinued }\end{array}$ & Yes \\
\hline \multicolumn{14}{|c|}{ Post-Traumatic Stress Disorder } \\
\hline $\begin{array}{l}\text { Ruggiero et } \\
\text { al. (2015) }\end{array}$ & $\begin{array}{l}3 \text { arms } \\
N=987\end{array}$ & $\begin{array}{l}12-17 \\
\text { yrs } \\
(14.5) \\
465 / 522\end{array}$ & $\begin{array}{l}\text { Prevention: } \\
\text { participants } \\
\text { included on } \\
\text { basis of } \\
\text { being } \\
\text { exposed to } \\
\text { tornado }\end{array}$ & $\begin{array}{l}\text { Bounce Back } \\
\text { Now: web- } \\
\text { based } \\
\text { intervention, } \\
\text { based upon } \\
\text { behavioural } \\
\text { principles, } \\
\text { motivational- } \\
\text { enhancement } \\
\text { and cognitive- } \\
\text { behavioural } \\
\text { approaches }\end{array}$ & 364 & $\begin{array}{l}4 \text { modules; } \\
\text { authors } \\
\text { anticipated } \\
\text { participants } \\
\text { would only } \\
\text { visit website } \\
\text { once. }\end{array}$ & $\begin{array}{l}\text { Online and } \\
\text { accessed in } \\
\text { participants' } \\
\text { own } \\
\text { environment } \\
\text { (e.g. home) }\end{array}$ & $\begin{array}{l}\text { 1) Bounce } \\
\text { Back Now + } \\
\text { Adult Self- } \\
\text { Help } \\
\text { intervention } \\
\text { 2) No } \\
\text { intervention }\end{array}$ & $\begin{array}{l}\text { 1) } \\
366 \\
\text { 2) } \\
257\end{array}$ & $\begin{array}{l}\text { 1)Adult Self- } \\
\text { Help } \\
\text { intervention was } \\
\text { accessed via } \\
\text { Bounce Back } \\
\text { Now, consisted } \\
\text { of } 7 \text { self-help } \\
\text { modules } \\
\text { 2) N/A }\end{array}$ & $\begin{array}{l}\text { 1) Online } \\
\text { 2) N/A }\end{array}$ & $\begin{array}{l}\text { Unsure: } n=233 \\
\text { families } \\
\text { (teenager or } \\
\text { parent) across } \\
\text { two } \\
\text { intervention } \\
\text { trial arms did } \\
\text { not complete } \\
>1 \\
\text { intervention } \\
\text { module }\end{array}$ & Yes $^{1}$ \\
\hline
\end{tabular}

Abbreviations: CBT - cognitive behavioural therapy; cCBT - computerised cognitive behavioural therapy; DHI - digital health intervention; FU - follow-up; mth - month; $\mathrm{nM} / \mathrm{nF}$ - number of males in sample / number of females in sample; N/A - not applicable; N/S - not stated in published paper; yrs = years old. Within the ITT analysis column: Studies marked with ${ }^{1}$ indicate that separate analyses were also performed with 'completers' (as defined by authors; usually meant completing all or certain percentage of intervention). Studies marked as 'Unsure' indicate uncertainty about whether ITT analyses were performed due to discrepancies in reporting or insufficient information reported in paper. 